\title{
Effects of adaptive cruise control and highly automated driving on workload and situation awareness: A review of the empirical evidence
}

\author{
Joost C.F. de Winter ${ }^{a, *}$, Riender Happee ${ }^{a}$, Marieke H. Martens ${ }^{\mathrm{b}, \mathrm{c}}$, Neville A. Stanton ${ }^{\mathrm{d}}$ \\ ${ }^{a}$ Department of BioMechanical Engineering, Faculty of Mechanical, Maritime and Materials Engineering, Delft University of Technology, Mekelweg 2, \\ 2628 CD Delft, The Netherlands \\ ${ }^{\mathrm{b}}$ Centre for Transport Studies, University of Twente, Drienerlolaan 5, 7522 NB Enschede, The Netherlands \\ ${ }^{\mathrm{c}}$ TNO Human Factors, Kampweg 5, 3769 DE Soesterberg, The Netherlands \\ ${ }^{\mathrm{d}}$ Transportation Research Group, Civil, Maritime, Environmental Engineering and Science, Engineering and the Environment, University of Southampton, \\ United Kingdom
}

\section{A R T I C L E I N F O}

\section{Article history:}

Received 15 October 2013

Received in revised form 9 June 2014

Accepted 26 June 2014

Available online 19 August 2014

\section{Keywords:}

Human Factors

Levels of automation

Driving simulator

Meta-analysis

NASA Task Load Index

Secondary task

Distraction

Attention

Eye movements

Psychophysiology

\begin{abstract}
A B S T R A C T
Adaptive cruise control (ACC), a driver assistance system that controls longitudinal motion, has been introduced in consumer cars in 1995. A next milestone is highly automated driving (HAD), a system that automates both longitudinal and lateral motion. We investigated the effects of ACC and HAD on drivers' workload and situation awareness through a meta-analysis and narrative review of simulator and on-road studies. Based on a total of 32 studies, the unweighted mean self-reported workload was $43.5 \%$ for manual driving, $38.6 \%$ for ACC driving, and $22.7 \%$ for $\operatorname{HAD}(0 \%=$ minimum, $100=$ maximum on the NASA Task Load Index or Rating Scale Mental Effort). Based on 12 studies, the number of tasks completed on an in-vehicle display relative to manual driving (100\%) was $112 \%$ for ACC and $261 \%$ for HAD. Drivers of a highly automated car, and to a lesser extent ACC drivers, are likely to pick up tasks that are unrelated to driving. Both ACC and HAD can result in improved situation awareness compared to manual driving if drivers are motivated or instructed to detect objects in the environment. However, if drivers are engaged in non-driving tasks, situation awareness deteriorates for ACC and HAD compared to manual driving. The results of this review are consistent with the hypothesis that, from a Human Factors perspective, HAD is markedly different from ACC driving, because the driver of a highly automated car has the possibility, for better or worse, to divert attention to secondary tasks, whereas an ACC driver still has to attend to the roadway.
\end{abstract}

(c) 2014 Elsevier Ltd. All rights reserved.

\section{Introduction}

The idea of fully automated driving is certainly not new. In 1863, Jules Verne envisioned a future Paris featuring driverless trains and carriages propelled by pneumatic and electromagnetic infrastructures (Verne, 1996). In the same period, the Beach Pneumatic Transit Company actually built a driverless wagon transporting passengers through a tunnel beneath Broadway (Beach, 1870). A scale model of an automated highway system was demonstrated at the 1939 New York World's

\footnotetext{
* Corresponding author.

E-mail address: j.c.f.dewinter@tudelft.nl (J.C.F. de Winter).
} 
Fair (Fotsch, 2001; Geddes, 1940). Between 1950 and 1990, various researchers in the United States, Europe, and Japan equipped consumer cars with systems that automatically controlled steering and speed (Shladover, 1995). In 1997, demonstrations of automated platooning and lane changing were held on a section of a highway in San Diego (Thorpe, Jochem, \& Pomerleau, 1997). Soon after the 1997 demonstrations, the stakeholders of the project agreed that a fully automated highway system was "too much of a 'conceptual leap"' (National Automated Highway System Consortium [NAHSC], 1998, p. 1).

Although many research projects allude to a revolutionary introduction of fully automated driving, the development of automated driving is better described as an evolutionary process. As early as the 1970s, Verplank (1977) stated that this evolution had already been going on for a long time through developments such as spark-advance, choke, automatic transmission, and cruise control, and he predicted that automatic headway and steering control would be introduced in the future. Adaptive cruise control (ACC) can be found in consumer cars since 1995 (Beiker, 2012). ACC is a system that controls longitudinal vehicle motion only and therefore qualifies as driver assistance according to the definition proposed by the German Federal Highway Research Institute (BASt) (Gasser \& Westhoff, 2012). Note that the Society of Automotive Engineers (SAE) and the National Highway Traffic Safety Administration (NHTSA) have introduced similar definitions of levels of driving automation (see Smith, 2013, for a comparison of definitions).

Developments in stereo cameras, radar, laser, and artificial intelligence have recently given rise to automation that can take over longitudinal and lateral control simultaneously. Some examples are Acura's ACC combined with Lane Keeping Assist (Acura, 2014), BMW's Traffic Jam Assistant (BMW, 2013), General Motor's Super Cruise (Fleming, 2012), Lincoln's Lane-Keeping System with ACC (Lincoln, 2014), Mercedes' Distronic Plus with Steering Assist (Daimler, 2013), Toyota's Automated Highway Driving Assist (Toyota, 2013), and Volvo's ACC with steer assistance (Volvo, 2013). For safety reasons, these systems require the driver to permanently monitor the road and/or intermittently touch the steering wheel (which can be detected by means of a torque sensor; Pohl \& Ekmark, 2003). These types of systems qualify as partial automation according to the BASt definition. A next step in technological evolution is highly automated driving (HAD) where the driver can release the hands from the steering wheel and is no longer required to permanently monitor the road. Note that with HAD the human still has to reclaim manual control occasionally, for example when the functional limitations of the automation are reached. A HAD system provides a warning signal in advance if manual takeover is required.

Until the driving task is wholly automated there will be an appreciable role for the human driver (Alecandri \& Moyer, 1992; Barfield \& Dingus, 1998; Fenton, 1970; Hancock \& Parasuraman, 1992; Sheridan, 1970). Many Human Factors researchers would probably agree that workload and situation awareness are two of the most important Human Factors constructs that are predictive of performance and safety (McCauley \& Miller, 1997; Parasuraman, Sheridan, \& Wickens, 2008; Sarter \& Woods, 1991; Stanton \& Young, 2000). Accordingly, the aim of this study is to quantify the effects of ACC and HAD on workload and situation awareness.

Workload and situation awareness are constructs rather than causal agents (Flach, 1995) and therefore require welldefined measurement procedures (Hand, 1996). We define workload as the outcome of questionnaires or tests that assess the cost (Hart \& Staveland, 1988) or difficulty (Fuller, 2005) experienced by the driver. HAD and ACC could raise workload with respect to manual driving if the driver has to remain vigilant and monitor the automation status. HAD, and to a lesser extent ACC, could also reduce workload, as the driver is relieved from the cognitive activity associated with manual driving and from the physical activity of moving the pedals and steering wheel. A review study by Dragutinovic, Brookhuis, Hagenzieker, and Marchau (2005) found that in 6 out of 6 driving simulator studies, ACC resulted in lower self-reported workload than manual driving, but quantitative results were not provided. The review of Dragutinovic et al. (2005) requires updating, because a large number of studies have been conducted since and because this review did not include studies on HAD.

We define situation awareness as "knowing what's going on so you can figure out what to do" (Adam, 1993, p. 319). Adam's definition parsimoniously captures the essence of situation awareness, including the classical formulation of Endsley (1988) which states that situation awareness is "the perception of the elements in the environment within a volume of time and space, the comprehension of their meaning and the projection of their status in the near future" (p. 97). Concerns have been expressed that HAD (Merat, Jamson, Lai, \& Carsten, 2010) and ACC (Carsten, 2004) lead to impoverished situation awareness. Situation awareness can be measured by testing whether the driver has observed and understood the host vehicle's state, the road infrastructure, objects in the environment, and the behaviours of other road users. A well-known technique is SAGAT (Situation Awareness Global Assessment Technique), an approach whereby the simulation is temporarily frozen and the screens blanked. During a simulation freeze, participants fill out a questionnaire sheet probing them about objects and conflicts in the environment. Situation awareness can also be operationalized as the driver's response during a critical event scenario, or it can be inferred from eye-movements.

Using our conceptual driver model in Fig. 1, we hypothesize that HAD induces a major change in workload and situation awareness compared to manual driving or driving with ACC. When using ACC, the control of speed and headway (task 1) is automated, but the driver still closes the lateral loop (task 2). Drivers who steer manually need to visually sample the road and apply steering corrections at least every $3 \mathrm{~s}$ (Godthelp, 1984). So when using ACC, there is little opportunity to divert visual attention to non-driving tasks. Directing attention away from the road to competing activities is generally regarded as unsafe, and is more commonly known as "driver distraction" (Ferdinand \& Menachemi, 2014; Foley, Young, Angell, \& Domeyer, 2013; Green, 1999; National Highway Traffic Safety Administration, 2012; Spiessl \& Mangold, 2010).

During HAD, the longitudinal and lateral control loops (tasks 1 and 2) are both automated and it therefore becomes possible to divert attention away from the road and to pick up other tasks, depending on incentives and motivation. If, 


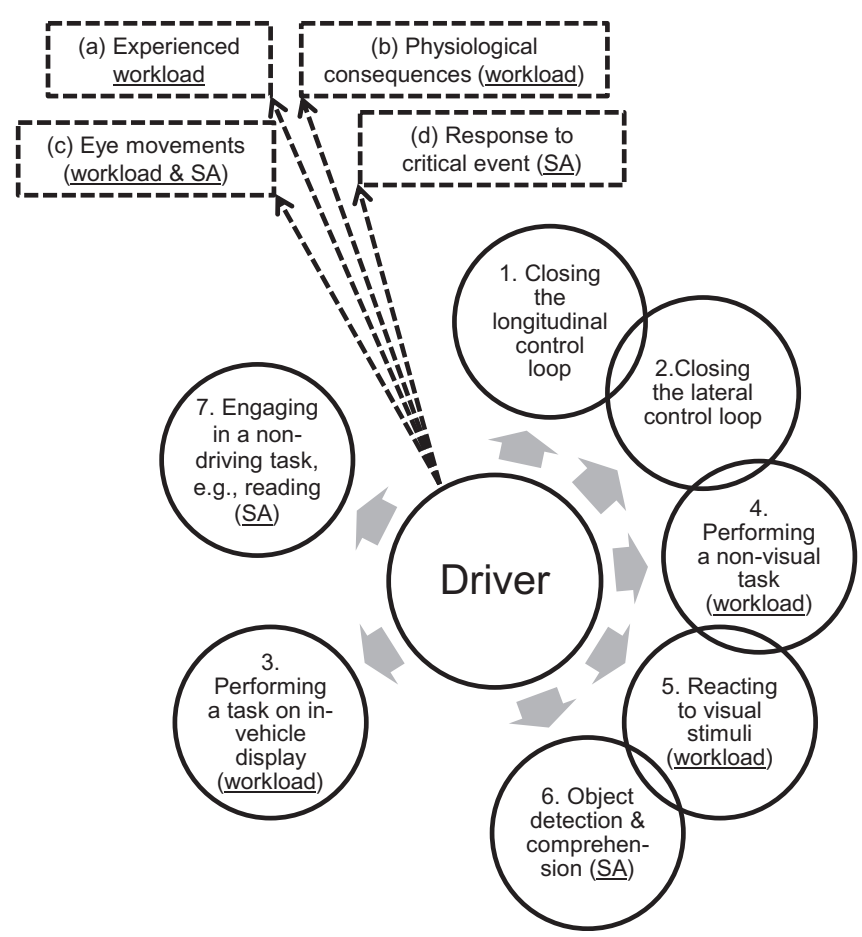

Fig. 1. Conceptualization of the driver's task. The driver can attend to six types of subtasks: (1) longitudinal vehicle control, (2) lateral vehicle control, (3) a task on an in-vehicle display used by an investigator to infer workload (a high score on this secondary task implies low workload), (4) a non-visual task used by an investigator to infer workload (a high score on this secondary task implies low workload), (5) a visual reaction-time task used by an investigator to infer workload, (6) scanning the environment (when the driver perceives and comprehends more objects in the environment, his/her situation awareness is better), (7) a non-driving task such as reading or sleeping (engaging in a non-driving task implies diminished knowledge of the environment and therefore low situation awareness). Tasks that can relatively easily be timeshared are depicted as a cluster of overlapping circles. Tasks that are mutually exclusive are represented as non-overlapping circles. For example, it is impossible to spend a prolonged time attending to an in-vehicle display (task 3 ) while having to close the longitudinal (task 1) and lateral (task 2) control loops. On the contrary, task 4 can be performed during driving, as it can be performed without taking the eyes off the road. The dashed rectangles represent offline or online measurements that can be used to infer the driver state. SA = Situation awareness.

for example, the driver of a highly automated car has been instructed by an experimenter to perform a task on an in-vehicle display as an indicator of workload (task 3), the driver will probably outperform an ACC driver at this task, and the experimenter will accordingly conclude that the driver of the highly automated car has a lower workload than the ACC driver. If the driver of a highly automated car has received no specific instructions, he or she may engage in non-driving tasks, such as using in-vehicle entertainment, reading a book, or reaching a rear compartment (task 7). Distraction from the road is associated with reduced situation awareness (Dozza, 2012; Rogers, Zhang, Kaber, Liang, \& Gangakhedkar, 2011; Young, Salmon, \& Cornelissen, 2012). Hence, engaging in 'task 7' will probably mean that the driver of the highly automated car will score poorly on a situation awareness test.

In addition to the driving tasks represented as clusters of circles, Fig. 1 also shows auxiliary dashed boxes representing ways to probe the driver's state. Several researchers have used physiological measurements for inferring workload (box b in Fig. 1). Eye gaze patterns (box c) are useful for inferring both situation awareness (Gugerty, 2011) and workload, with reduced variance of gaze associated being indicative of higher workload (Victor, Harbluk, \& Engström, 2005). We expect that drivers in a highly automated car are more likely to direct their attention away from the road than manual drivers and ACC drivers, because HAD drivers are more likely to engage in tasks 3, 6, and 7 of Fig. 1. In the remainder of this article, we will review the effect of ACC and HAD on workload and situation awareness, using the conceptual driver model in Fig. 1.

\section{Method}

\subsection{Study eligibility criteria}

We included only studies that evaluated ACC versus manual driving, HAD versus manual driving, and/or ACC versus HAD. For the purpose of our literature review, we defined ACC as any system that automatically maintained headway to a vehicle in front while the driver steered manually, and we defined HAD as any system in which longitudinal and lateral control were 
simultaneously taken over by the automation. Consistent with the research aims and the driver model proposed in Fig. 1, we included studies with at least one of the following measures:

(1) self-reported workload using a questionnaire after driving (box a).

(2) performance on a self-paced in-vehicle display task (task 3).

(3) physiological measurements while driving (box b).

(4) performance on a non-visual task (task 4).

(5) reaction times to artificial visual stimuli (task 5).

(6) eye-movement (box c).

(7) performance on tests of object detection and/or comprehension (task 6).

(8) measures describing whether drivers picked up tasks that are unrelated to driving, such as eating or reading (task 7).

(9) drivers' response to critical events in the environment (box d).

Categories 1-5 were used to assess workload, and categories 7-9 were used to assess situation awareness. Eyemovements (category 6) were used to assess both workload and situation awareness. Studies that did not evaluate any of the above nine categories, but instead used other types of self-reports (e.g., ratings of acceptance, arousal, comfort, fatigue, feeling of risk, trust, or stress), vehicle-centred measures (e.g., lateral position, headway, speed, time-to-line crossing), or self-reported situation awareness (e.g., Situation Awareness Rating Technique [SART, Stanton \& Young, 2005] or the Mission Awareness Rating Scale [MARS]) were not included. To obtain a relatively homogeneous metric for category 1, we included only those studies that used the NASA Task Load Index (TLX) or Rating Scale Mental Effort (RSME). Hence, studies that used custom mental demand, effort, or task-difficulty scales (e.g., Ma \& Kaber, 2005; Nowakowski, O'Connell, Shladover, \& Cody, 2010; Piccinini et al., 2013; Vollrath, Briest, \& Oeltze, 2010; Volvo, 2004) were not included in category 1. Both driving simulator studies and studies in real cars were included. Studies in which the automation occasionally malfunctioned or in which the driver was required to take over manual control were eligible for inclusion. However, studies in which drivers used the automation less than 75\% of the driving time (e.g., Gempton, Skalistis, Furness, Shaikh, \& Petrovic, 2013; Neubauer, Matthews, Langheim, \& Saxby, 2012; Van Driel \& Van Arem, 2006) were not included in category 1, since extensive periods of manual driving were expected to dilute post-drive workload ratings. The work by Sterling, Perala, and Blaske (2007) was excluded because it evaluated crews of operators, rather than individual drivers. All types of publications (including conference proceedings, theses, and reports) were eligible. However, studies in non-Latin languages (Kuo, 2006) were not included because of limited accessibility and the practical difficulties of translation.

\subsection{Literature search methods}

Our literature search was conducted using Google Scholar, because this search engine adopts full-text search and has broad coverage (De Winter, Zadpoor, \& Dodou, 2014; Gehanno, Rolin, \& Darmoni, 2013; Shariff et al., 2013). Searches were performed in January 2014 with the Publish or Perish software (Harzing, 2011) using one of the five following keywords: "automated driving" "automatic steering", "automatic driving", "automated highway", "adaptive cruise control" combined with one of the five following keywords: "human factors", "secondary task", "situation awareness", "workload", and "eye-tracking", resulting in 25 individual searches. Several additional searches were performed of sources that are not fully covered by Google Scholar (i.e., Web of Knowledge, http://www.ntis.gov, \& http://trid.trb.org) with search terms related to workload, situation awareness, and automated driving. Furthermore, a selective updated Google Scholar search was conducted in March and June 2014, and various authors were contacted for retrieving potentially eligible studies. The reference lists of all included studies were checked for further eligible studies. When workload or situation awareness data were not (clearly) reported, we attempted to contact the authors for further information.

\subsection{Meta-analysis versus narrative review as a synthesis approach}

A meta-analysis is a preferred tool for synthesizing results across studies, but is feasible only when the included studies address the same research question and use similar dependent measures. We deemed a meta-analysis to be feasible for the first two research categories mentioned in Section 2.1 (i.e., workload measured with a questionnaire and workload based on performance on a self-paced in-vehicle display task). For the other seven categories we offered a narrative review of the quantitative evidence.

A methodological decision that has to be made prior to conducting a meta-analysis is whether to use a random effects or fixed effect model (Hedges \& Vevea, 1998). We synthesized the available data in both ways: by weighting each study according to their sample size (resembling a fixed effect meta-analysis) and by assigning equal weight to the individual studies (corresponding to a random effects meta-analysis when effects would be extremely heterogeneous).

\subsection{Extracted variables for meta-analysis}

For each included study, we extracted the self-reported workload scores and the performance on the self-paced in-vehicle display task for the manual, ACC, and HAD conditions. Studies that provided incomplete data or selective results based on 
statistical significance (e.g., Davis, Animashaun, Schoenherr, \& McDowell, 2008; Desmond, Hancock, \& Monette, 1998; Flemisch et al., 2008; Ward, Fairclough, \& Humphreys, 1995) were not included. If data were not available in numerical form but provided in a figure, we used graphics software to extract the numerical values. To enable a comparison across studies, we converted the self-reported workload into a percentage using the minimum and maximum units on the scale. For example, the RSME scale runs from 0 to $150 \mathrm{~mm}$, and the scores were therefore divided by 1.5 to obtain a workload score from $0 \%$ to $100 \%$. The performance on the visual task was linearly scaled such that the score for the manual condition was $100 \%$. For example, if drivers completed on average 20 tasks per minute during HAD and 10 tasks per minute during manual driving, then the converted scores were $200 \%$ and $100 \%$, respectively. If workload was measured at different time instances or for different conditions (e.g., types of ACC, types of traffic conditions, types of visibility conditions) then the arithmetic mean across these dimensions/instances was calculated. If both the TLX and RSME scores were reported, we used only the TLX in the meta-analysis.

\subsection{Summary measures for meta-analysis}

We used the raw means for meta-analysis, because raw data is more easily interpreted than a standardized effect size (Bond, Wiitala, \& Richard, 2003). The choice for raw means also reflects a practical necessity, because many studies did not report the standard deviations of the workload scores, as a result of which calculating a standardized effect size was impossible.

\section{Results}

Our searches in Google Scholar yielded 4271 titles. If the title of the article was related to Human Factors and transportation then the abstract or full text was read. Twenty-one studies fulfilled the inclusion criteria of categories 1 and 2 of Section 2.1. Using additional search methods, 16 more studies were included. Accordingly, the meta-analysis of self-reported workload and performance on a self-paced in-vehicle display task included 37 studies and 1049 participants (Table 1).

\subsection{Meta-analysis of self-reported workload measured using a questionnaire after driving}

Thirty-two studies were included that evaluated workload by means of a questionnaire. ACC resulted in lower selfreported workload than manual driving in 22 out of 24 studies (grey versus white bars in Fig. 2). HAD resulted in lower self-reported workload than manual driving in 15 out of 15 studies (black versus white bars). The mean workload, assigning equal weight to each study (sample-size weighted means between parenthesis) was $43.5 \%$ (42.9\%) for manual driving, 38.6\% (38.9\%) for ACC driving, and 22.7\% (23.7\%) for HAD. In other words, ACC results in a relatively small reduction of workload and $\mathrm{HAD}$ results in a large reduction of workload compared to manual driving.

\subsection{Meta-analysis of workload measured as performance on a self-paced in-vehicle display task}

Twelve studies used a self-paced visual task paradigm to measure workload with ACC and/or HAD versus manual driving (Fig. 3). In 9 out of 10 studies (grey versus white bars), more secondary tasks were completed with ACC than with manual driving. In 9 out of 9 studies, more secondary tasks were solved with HAD than with manual driving (black versus white bars). The mean number of tasks completed (sample-size weighted means between parenthesis) was $100 \%$ for manual driving, $112 \%$ (111\%) for ACC, and 261\% (252\%) for HAD. In other words, when using ACC, drivers are able to complete approximately $12 \%$ more tasks on a visual display than when driving manually. However, for HAD, drivers are able to over 2.5 times as many tasks than when driving manually.

\subsection{Workload measured through physiological measurements}

It has been found that HAD reduces skin conductance (Cha, 2003), increases eye-blink rate (Cha, 2003; Damböck et al., 2013; Merat, Jamson, Lai, \& Carsten, 2012), and increases the percentage of time that drivers close their eyes (Jamson, Merat, Carsten, \& Lai, 2013) compared to manual driving. Various ACC and HAD studies have measured heart rate variability (e.g., Brookhuis, Van Driel, Hof, Van Arem, \& Hoedemaeker, 2009; De Waard et al., 1999; Mayser, Piechulla, Weiss, \& König, 2003; Takada \& Shimoyama, 2001; Takano \& Kobayashi, 2004; Törnros et al., 2002; Uyttendaele \& Terken, 2014; Wille, Röwenstrunk, \& Debus, 2007). However, algorithms for calculating heart rate variability are diverse, which makes a quantitative synthesis problematic. Heart rate appears to be the most commonly used physiological measure, and will be reviewed below.

\subsubsection{Heart rate for ACC versus manual driving}

In what appears to be a single-subject study in real traffic, Kondo, Asanuma, Ishida, Ikegaya, and Tanaka (1999) found that the driver's heart rate was higher for ACC driving as compared to manual driving ( 57.7 vs. 53.8 beats/min). The driver's heart rate clearly decreased with driving time across the two-hour drive (from 58 to 52 beats/min averaged across the two 
Table 1

Overview of meta-analysed studies measuring self-reported workload and/or performance on a self-paced in-vehicle display task.

\begin{tabular}{|c|c|c|c|c|c|c|c|c|c|c|c|c|c|c|c|c|c|}
\hline \multirow[t]{2}{*}{$\mathrm{Nr}$} & \multirow[t]{2}{*}{ Authors } & \multicolumn{2}{|c|}{$\begin{array}{l}\text { Workload } \\
(\%)\end{array}$} & \multirow[b]{2}{*}{ HAD } & \multirow[b]{2}{*}{ Scale } & \multicolumn{4}{|c|}{ Number of tasks solved } & \multirow[b]{2}{*}{ Apparatus } & \multirow[b]{2}{*}{$\begin{array}{l}\text { Critical } \\
\text { event }\end{array}$} & \multirow[b]{2}{*}{$\begin{array}{l}\text { Duration } \\
\text { (hours) }\end{array}$} & \multirow[b]{2}{*}{$N$} & \multirow[b]{2}{*}{ Age } & \multirow[b]{2}{*}{$\begin{array}{l}\text { Females } \\
\text { (\%) }\end{array}$} & \multirow[b]{2}{*}{ Design } & \multirow[b]{2}{*}{ Vehicle } \\
\hline & & $\mathrm{M}$ & ACC & & & M & ACC & HAD & Type of task & & & & & & & & \\
\hline 1 & Bjørkli, Jenssen, Moen, and Vaa (2003) & 41 & 43 & & TLX & & & & & $\mathrm{SimH}$ & No & 0.14 & 18 & & & W & Car \\
\hline 2 & $\begin{array}{l}\text { Brook-Carter, Parkes, Burns, and Kersloot } \\
(2002)\end{array}$ & 46 & 32 & & TLX & & & & & SimM & No & & 28 & 42.5 & 50 & W & Car \\
\hline 3 & $\begin{array}{l}\text { Damböck, Weißgerber, Kienle, and Bengler } \\
(2013)^{*}\end{array}$ & 55 & & 33 & TLX_lh & & & & & SimM & Yes & 1.67 & 24 & 30.5 & 17 & W & Car \\
\hline 4 & $\begin{array}{l}\text { De Waard, Van der Hulst, Hoedemaeker, } \\
\text { and Brookhuis (1999) }\end{array}$ & 24 & & 11 & RSME & & & & & SimM & Yes & 0.93 & 20 & 29.8 & 20 & W & Car \\
\hline 5 & $\begin{array}{l}\text { De Winter, Stanton, Price, and Mistry } \\
\text { (2014) }\end{array}$ & 32 & & 31 & TLX_vlvh & & & & & SimL & Yes & 0.88 & 24 & 27.4 & 38 & W & Car \\
\hline 6 & De Winter et al. (2014) & 43 & 37 & 31 & TLX_vlvh & & & & & SimM & Yes & 0.48 & 27 & 21.5 & 41 & W & Car \\
\hline 7 & Flemisch et al. (2008) & & & & & 6.6 & & 35.2 & Visual search & $\mathrm{SimH}$ & Yes & 0.19 & 10 & 32.7 & 50 & W & Car \\
\hline 8 & $\begin{array}{l}\text { Flemisch, Kaussner, Petermann, Schieben, } \\
\text { and Schöming (2011) }\end{array}$ & & & & & 14.2 & & 35.0 & Menu navigation & $\mathrm{SimH}$ & Yes & 1.00 & 12 & 27.0 & 42 & W & Car \\
\hline 9 & Freitag et al. (2004) & 42 & 37 & & TLX_vlvh & & & & & SimM & Yes & 0.50 & 11 & & 50 & B & Car \\
\hline 10 & Funke, Matthews, Warm, and Emo (2007) & 34 & 32 & & TLX_lh & & & & & SimL & No & 0.92 & 56 & 20.4 & 59 & B & Car \\
\hline 11 & Hoedemaeker $(1999)^{\#}$ & 31 & 26 & & RSME & & & & & SimM & Yes & 1.63 & 30 & 38.8 & 20 & W & Car \\
\hline 12 & Hoedemaeker and Kopf (2001) & 23 & 20 & & TLX & & & & & Real & Yes & 1.50 & 8 & 32.5 & 0 & W & Car \\
\hline 13 & Ma (2006) & 57 & 37 & & TLX_lh & & & & & SimL & No & 1.00 & 10 & 28.1 & & B & Car \\
\hline 14 & $\begin{array}{l}\text { Martens, Wilschut, and Pauwelussen } \\
\text { (2008) }\end{array}$ & 25 & 25 & 18 & RSME & & & & & SimH & Yes & 1.58 & 14 & 47.6 & 33 & B & Car \\
\hline 15 & $\begin{array}{l}\text { McDowell, Nunez, Hutchins, and Metcalfe } \\
\text { (2008) }\end{array}$ & 51 & & 40 & TLX & & & & & Real & No & 2.68 & 11 & 33.0 & 0 & w & Truck \\
\hline 16 & Nilsson and Nåbo (1996) & 42 & 39 & & TLX_vlvh & & & & & SimH & No & 1.13 & 20 & 35.7 & 50 & B & Car \\
\hline 17 & Nilsson (1995) & 34 & 31 & & TLX_vlvh & & & & & SimH & Yes & 1.00 & 10 & 36.0 & 50 & B & Car \\
\hline 18 & Peters (2001) & 32 & 28 & & TLX_vlvh & & & & & SimH & No & 1.05 & 20 & 39.8 & 15 & W & Car \\
\hline 19 & Rudin-Brown and Parker (2004) & 34 & 29 & & TLX_vlvh $^{* *}$ & 3.9 & 4.4 & & $\begin{array}{l}\text { Visual search \& } \\
\text { scrolling }\end{array}$ & Real & Yes & 2.00 & 18 & 27.5 & 22 & W & Car \\
\hline 20 & Saffarian, Happee, and De Winter (2012) & 32 & 27 & & TLX_vlvh & & & & & SimM & No & 0.47 & 27 & 28.9 & 19 & W & Car \\
\hline 21 & $\begin{array}{l}\text { Saxby, Matthews, Warm, Hitchcock, and } \\
\text { Neubauer (2013) }\end{array}$ & 43 & & 34 & TLX_lh & & & & & $\operatorname{SimL}$ & No & 0.55 & 36 & 19.9 & 61 & $\mathrm{~B}$ & Car \\
\hline 22 & Saxby et al. (2013) & 29 & & 27 & TLX_lh & & & & & $\operatorname{SimL}$ & Yes & 0.45 & 56 & 19.4 & 64 & $\mathrm{~B}$ & Car \\
\hline 23 & Schermers, Malone, and Van Arem (2004) & 39 & & 23 & RSME & & & & & SimH & Yes & 1.25 & 18 & 40.0 & 0 & W & Truck \\
\hline 24 & Stanton, Young, and McCaulder (1997) ${ }^{\#}$ & & & & & 22.2 & 31.3 & & Figure comparison & SimM & Yes & 0.17 & 12 & 21.0 & 50 & W & Car \\
\hline 25 & $\begin{array}{l}\text { Stanton, Young, Walker, Turner, and } \\
\text { Randle (2001) }\end{array}$ & & & & & 73.3 & 77.9 & 152.6 & Figure comparison & SimM & Yes & 0.83 & 20 & 26.0 & 50 & W & Car \\
\hline 26 & Tango, Minin, Aras, and Pietquin (2011) & 64 & 59 & & TLX_lh & & & & & SimM & Yes & 1.71 & 10 & 31.0 & 50 & W & Car \\
\hline 27 & $\begin{array}{l}\text { Törnros, Nilsson, Ostlund, and Kircher } \\
\text { (2002) }\end{array}$ & 38 & 34 & & TLX & & & & & $\mathrm{SimH}$ & No & 1.48 & 24 & 40.0 & 50 & W & Car \\
\hline 28 & Uyttendaele and Terken (2014) & 58 & 34 & & RSME & & & & & SimL & No & 0.01 & 29 & 22.0 & 30 & W & Car \\
\hline 29 & $\begin{array}{l}\text { Van der Hulst, Rothengatter, and Heino } \\
\text { (1996) }\end{array}$ & 33 & 25 & & RSME & & & & & SimM & Yes & & 20 & 27.0 & 50 & B & Car \\
\hline 30 & Vollrath et al. (2010) & & & & & 87.7 & 86.3 & & Visual search & SimH & Yes & 3.00 & 22 & 38.0 & 45 & W & Car \\
\hline 31 & Young (2000) & & 52 & 23 & TLX_lh & & & & & SimM & No & 0.42 & 18 & 21.7 & 28 & W & Car \\
\hline 32 & Young and Stanton (2004) & 54 & 42 & 12 & TLX_lh & 129.0 & 136.8 & 200.5 & Figure comparison & SimM & No & 0.92 & 12 & 24.7 & 67 & W & Car \\
\hline
\end{tabular}


34 Young and Stanton (2007)

35 Young and Stanton (2007)

$\begin{array}{llll}61 & 47 & 12 & \text { TLX_lh } \\ 66 & 57 & 11 & \text { TLX_lh } \\ 65 & 59 & 13 & \text { TLX_lh } \\ 63 & 61 & 20 & \text { TLX_lh } \\ 59 & 54 & 24 & \text { TLX_lh }\end{array}$

$\begin{array}{lllll}125.0 & 146.6 & 223.8 & \text { Figure comparison } & \text { SimM } \\ 58.7 & 71.9 & 203.1 & \text { Figure comparison } & \text { SimM } \\ 70.7 & 74.8 & 196.2 & \text { Figure comparison } & \text { SimM } \\ 108.5 & 111.3 & 214.3 & \text { Figure comparison } & \text { SimM } \\ 84.0 & 92.4 & 176.4 & \text { Figure comparison } & \text { SimM }\end{array}$

No

(hours)

37 Young and Stanton (2007)

$\begin{array}{ll}69 & 54\end{array}$

TLX_lh

$\begin{array}{lllll}84.0 & 92.4 & 176.4 & \text { Figure comparison } & \text { SimM }\end{array}$

No

0.92

0.92
0.92

$\begin{array}{lll}12 & 28.6 & 33\end{array}$

: $\mathrm{M}=$ Manual driving; $\mathrm{ACC}=$ adaptive cruise control; HAD = highly automated driving; $\mathrm{W}=$ Within-subjects design; $\mathrm{B}=$ Between-subjects design; TLX_lh = Raw NASA Task Load Index ranging from low to high; TLX_vlvh = Raw NASA Task Load Index ranging from very low to very high; RSME = Rating Scale Mental Effort; SimL = low fidelity driving simulator defined as a desktop based simulator or a simulator

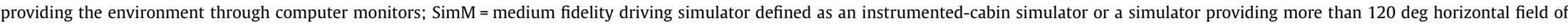

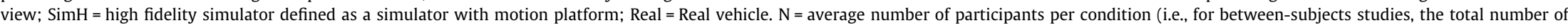
participants is $N * 2$ or $N * 3$ ). Duration of the experiment represents the total driving time including training sessions. When not reported in the paper, the mean age and duration of the experiment were estimated/derived based on the data reported in the paper. The works of De Winter et al. (2014), Saxby et al. (2013), and Young and Stanton (2007) included more than one study.

Only the results of the hands-off condition were used.

Not including the physical demands item.

\# All participants drove under the manual driving condition first (i.e., conditions not counterbalanced/randomized). 


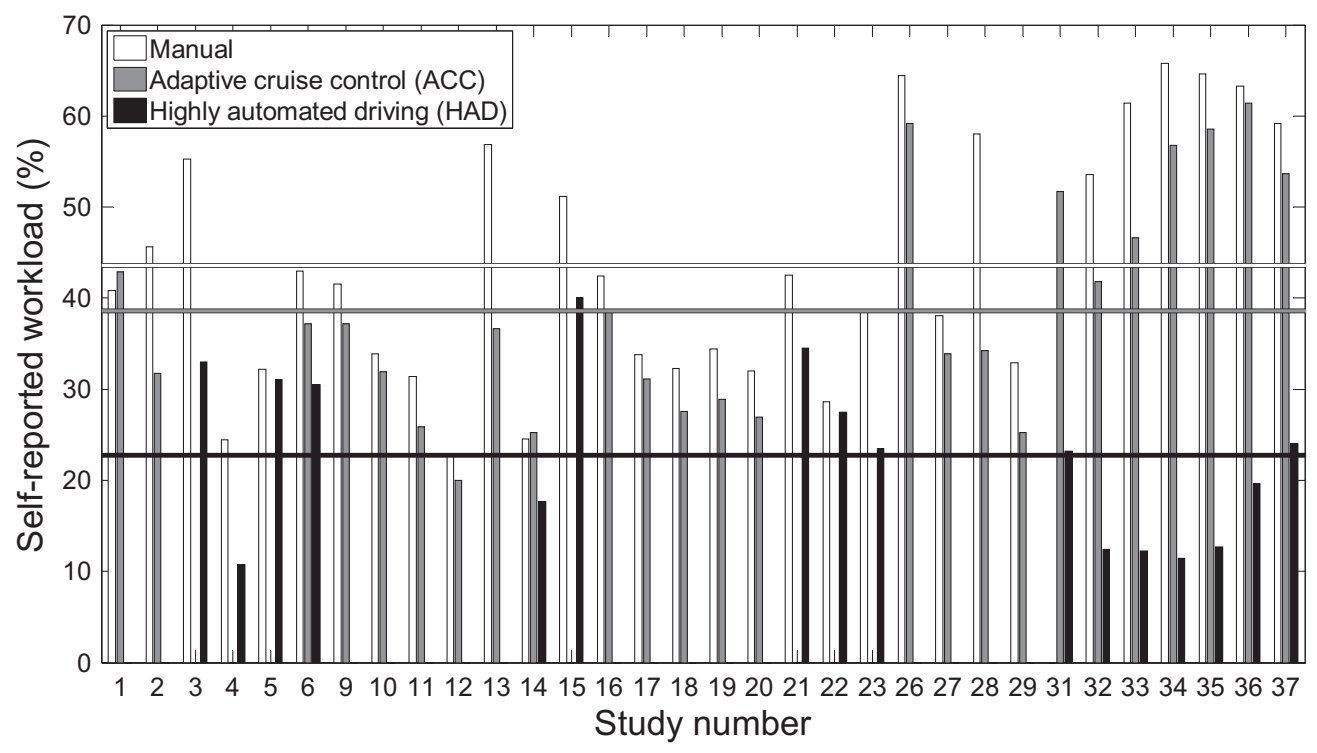

Fig. 2. Self-reported workload percentages by study number. The horizontal lines represent the mean across studies, assigning equal weight to each study. The study numbers correspond to Table 1.

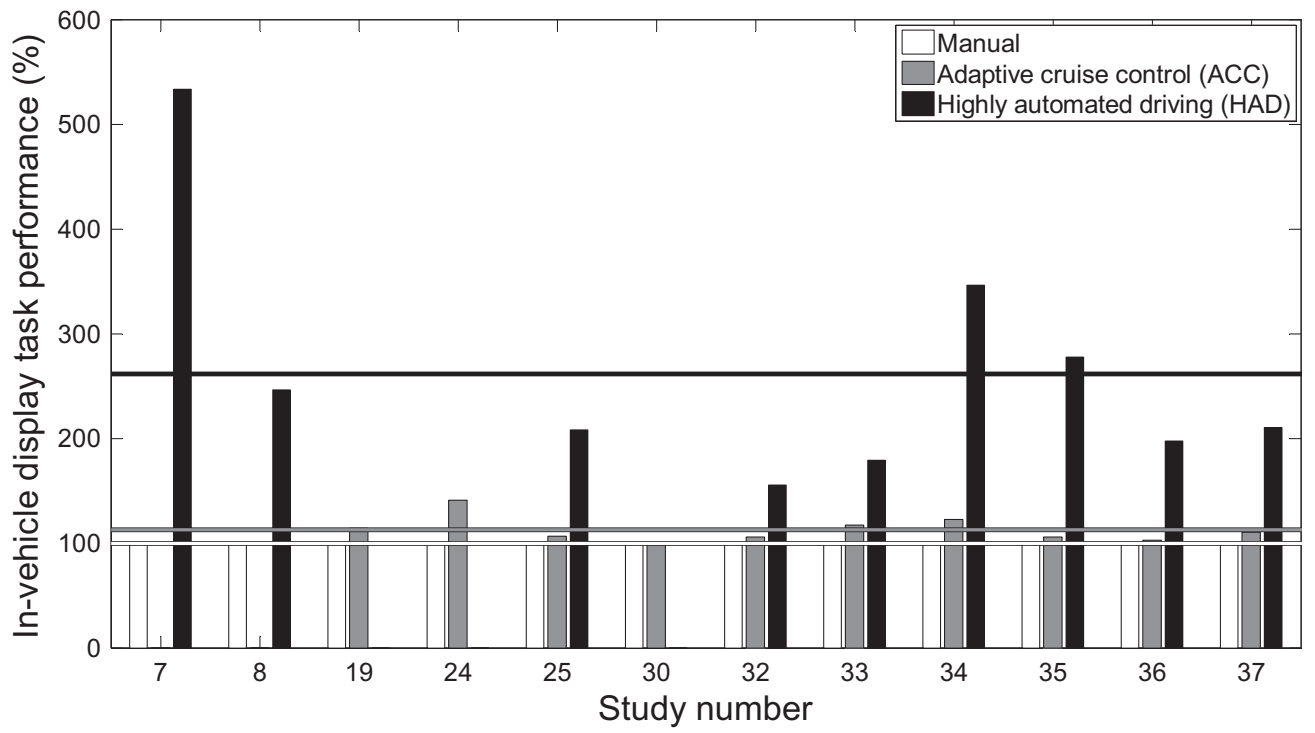

Fig. 3. The number of visual tasks completed by study number. For each study, the results of manual driving are normalized at $100 \%$, allowing for a meaningful comparison between the three conditions. The horizontal lines represent the means across studies, assigning equal weight to each study. The study numbers correspond to Table 1.

conditions). A simulator study by Vollrath et al. (2010) found lower heart rate for ACC driving compared to manual driving (74.6 vs. 76.3 beats/min, $N=17$ ). Again, a time-on-task effect was observed, with lower heart rates in the second half of the experiment compared to the first half ( 77.5 vs. 74.4 beats/min; average of both conditions). A driving simulator study by Hoedemaeker (1999) found similar heart rates for ACC and manual driving ( 74.8 vs. 74.8 beats $/ \mathrm{min}$; $N=30$ ), but the conditions were not randomized as all drivers started the experiment in the manual condition. In another driving simulator study, Uyttendaele and Terken (2014) found a mean heart rate of 71.4 beats/min for ACC and 76.0 for manual driving $(N=29)$, an effect which was statistically significant. However, in this study the manual and ACC conditions were not randomized either. A simulator study by Van Driel and Van Arem (2006) found a lower heart rate when driving with a congestion assistant compared to manual congestion driving ( 69.8 vs. 71.3 beats $/ \mathrm{min} ; N=37$ ). Törnros et al. (2002) observed a lower heart rate when driving with ACC as compared to driving manually ( 75.3 vs. 77.6 beats $/ \mathrm{min} ; N=8$ ), but this effect may be inflated as some non-significant results were not reported. 


\subsubsection{Heart rate for $H A D$ versus manual driving}

A simulator study by Carsten, Lai, Barnard, Jamson, and Merat (2012) found that the mean heart rate was 82.3 beats $/ \mathrm{min}$ for manual driving, 78.0 for ACC driving, and 75.6 for $\operatorname{HAD}(N=49$ for manual and HAD, and $N=25$ for ACC). All participants started in the manual condition and drove the final session in the HAD condition. A driving simulator study by De Waard et al. (1999) found that heart rate was slightly lower for HAD than for manual driving (73.2 vs. 74.0 beats/min). A simulator study by Wille et al. (2007) found a higher mean heart rate in highly automated truck driving compared to manual driving (72.4 vs. 70.3 beats/min; $N=16$ ), an effect which was not statistically significant. A driving simulator study by Young (2000) found lower heart rate for HAD than for ACC (78.9 vs. 84.8 beats/min, $N=44$ ). No clear time-on-task effects were found in their 10-min driving sessions.

\subsubsection{Summary}

The above studies show that both ACC and HAD tend to reduce heart rate as compared to manual driving, indicating a reduction of workload. However, not all studies are consistent in this respect. A number of studies have found time-on-task effects, whereby heart rate drops as participants become more accustomed to the experiment.

\subsection{Workload measured as performance on a non-visual task}

\subsubsection{ACC versus manual driving}

A simulator study by Nilsson and Nåbo (1996) used a working memory span test performed via a hands-free telephone ( $N=20$ for both the ACC and manual groups). The number of correct judgements (i.e., sensible or nonsense) and the number of correctly recalled words were about the same for the ACC and manual groups (67.0 vs. 67.3; 42.4 vs. 44.7). In another driving simulator study (Seppelt \& Lee, 2007; $N=24$ ), participants were required to listen and verbally respond to messages related to upcoming restaurants. The authors found no statistically significant differences between ACC and manual conditions (quantitative results not reported). In a driving simulator study by Hoedemaeker (1999), participants had to add up the total length of traffic congestions reported through the car radio $(N=38)$. Again, the task performance was not statistically different between ACC and manual driving. Takada and Shimoyama (2001) found slightly better performance on a mental calculation task for ACC as compared to manual driving (accuracy rate: 96\% vs. 93\%; response time $2.85 \mathrm{~s}$ vs. $2.87 \mathrm{~s} ; N=6$ ).

\subsubsection{HAD versus manual driving}

A simulator study by Merat et al. (2010, see also 2012) found no statistically significant difference in secondary task performance between manual driving and HAD. The secondary task was the Twenty Questions Task, requiring the participants $(N=49)$ to guess an item from within an overriding category by asking a maximum of 20 questions. The response to each question was binary (i.e., either yes or no). Secondary task performance was measured by the number of guesses and the number of questions asked.

\subsubsection{Summary}

Workload measured with non-visual tasks shows no significant differences between HAD/ACC and manual driving. However, the number of experiments using non-visual tasks is small.

\subsection{Workload measured as reaction time to artificial visual stimuli}

\subsubsection{ACC versus manual driving}

In a study by Brook-Carter et al. (2002), a red rectangle appeared on the simulator screen and the participant had to respond as quickly as possible by pressing the horn. The reaction time was slightly faster for driving with ACC than for manual driving (1.23 vs. $1.39 \mathrm{~s} ; N=28$ ). Similarly, Nilsson and Nåbo (1996) measured drivers' reaction time from the appearance of a red square until the participants pressed a button on the steering wheel. The red square was presented four times along the test route. Both the ACC group and the manual group had a mean reaction time of $1.18 \mathrm{~s}$. Peters (2001) found slightly shorter reaction times for ACC compared to manual driving in response to a total of four red squares that appeared on the screen during driving ( $1.32 \mathrm{vs.}$ $1.44 \mathrm{~s} ; N=20$ ). In a driving simulator study by Ma (2006), participants were requested to press a button on the steering wheel when the navigation aid was activated, which occurred after about 9 min of driving. A considerably faster mean response time was observed for the ACC group than for the manual group (2.1 vs. $4.2 \mathrm{~s} ; N=10$ per group). Van Driel and Van Arem (2006) found shorter mean peripheral detection times when driving with a low-speed ACC system in a traffic jam as compared to driving manually in the traffic jam (0.49 vs. $0.52 \mathrm{~s} ; N=34$ ). Törnros et al. (2002) found no statistically significant differences between manual and ACC driving on a peripheral detection task ( $N=8$; quantitative data not reported). Uyttendaele and Terken (2014) measured reaction times to blue LED lamps lighting every 20-40 s on the centre screen of the simulator. The mean reaction time was $0.51 \mathrm{~s}$ for ACC driving and $0.60 \mathrm{~s}$ for manual driving $(N=29)$. The ACC group had fewer misses (defined as a reaction time longer than $1.5 \mathrm{~s})$ than the manual group (11.2\% vs. $25.6 \%)$.

\subsubsection{HAD versus manual driving}

De Winter et al. (2014) found that drivers responded faster to arrow-shaped stimuli projected on the simulator screen during HAD as compared to manual driving (1.80 vs. $1.94 \mathrm{~s}$ in Experiment 1, $N=24$, and 1.35 vs. $1.97 \mathrm{~s}$ in Experiment 2, 
$N=27$ ). The percentages of missed stimuli were lower as well during HAD versus manual driving (7\% vs. $15 \%$ in Experiment 1, 5\% vs. 15\% in Experiment 2). Furthermore, participants reacted slightly faster to a stop sign projected on the screen with HAD as compared to manual driving ( 0.87 vs. $0.93 \mathrm{~s}$ in Experiment 2$)$. In Cha (2003), participants $(N=25)$ had to react to a red lamp by means of a push switch. The mean reaction time was $1.734 \mathrm{~s}$ for HAD versus $1.062 \mathrm{~s}$ for manual driving. The author reported that many drivers complained of drowsiness during their three HAD sessions of about 10 min each.

\subsubsection{Summary}

There are indications that ACC frees up mental capacity such that drivers respond faster to artificial visual stimuli than manual drivers. However, for HAD, it seems that drivers are susceptible to drowsiness, such that reaction times are slower than during manual driving.

\subsection{Situation awareness and workload measured from eye movement}

\subsubsection{ACC versus manual driving}

A simulator study by Park, Sung, and Lee (2006; see also Cho, Nam, \& Lee, 2006; Lee, Sung, Lee, Kim, \& Cho, 2007) reported two-dimensional plots of gaze direction, suggesting that ACC drivers have a higher spread of gaze than manual drivers. However, these results are difficult to interpret since no statistical analysis was provided.

\subsubsection{HAD versus manual driving}

A simulator study by Barnard and Lai (2010) found that drivers $(N=12)$ are less likely to direct their gaze to the road centre during HAD as compared to during manual driving, when instructed to do a non-driving task. The corresponding percentages of gaze time to the centre of the road were $40 \%$ vs. $62 \%$ for a video-watching task, $60 \%$ vs. $74 \%$ for a hand-held phoning task, $51 \%$ vs. $74 \%$ for an eating task, $20 \%$ vs. $47 \%$ for a map reading task, and $15 \%$ vs. $35 \%$ for an ipAQ task using a stylus. Carsten et al. (2012) found that drivers of a highly automated car were less likely to look at the road compared to manual drivers ( $53 \%$ vs. $72 \%$ of the time, $N=49$ ). A test-track study by Llaneras, Salinger, and Green (2013) found that drivers increased the proportion of time looking away from the forward roadway under HAD by 33\% relative to ACC driving, measured through eccentric head turns (see also Salinger, 2012). In a driving simulator study by the same research team, considerably stronger effects were observed, with about 2-3 times as many eccentric head turns during HAD than during ACC driving (Salinger, 2012; $N=63$ ). Finally, Damböck et al. (2013) found a higher standard deviation of horizontal gaze angle for HAD as compared to manual driving (8.1 deg vs. $6.1 \mathrm{deg} ;=24$ ).

\subsubsection{Summary}

HAD drivers are less likely to gaze at the road centre than manual drivers, which indicates that they have lower workload and altered situation awareness compared to manual driving. Eye movement differences between ACC and manual driving are inconclusive.

\subsection{Situation awareness measured with tests of object detection and comprehension}

\subsubsection{ACC versus manual driving}

A simulator study by Ma and Kaber (2005) found higher scores on SAGAT queries for ACC driving than for manual driving: the mean SAGAT scores were $83 \%$ versus $68 \%(N=9$ per group in a between-subjects study). These effects were replicated in a follow-up study (77\% vs. 52\%; $N=20$; Ma, 2006). In a driving simulator study by Funke et al. (2007), participants driving with ACC detected significantly more pedestrians who began to walk into the roadway than participants driving manually (33.6 vs. 31.3 of a maximum of 56 pedestrians; $N=28$ per condition). Brook-Carter et al. (2002) reported that the difference in SAGAT responses between driving with or without ACC was not statistically significant, but quantitative results were not provided $(N=32)$. In another driving simulator study, it was found that 10 of 15 participants driving with ACC could remember at least 1 of 4 traffic signs compared to 14 out of 15 participants driving manually (Kassner et al., 2011).

\subsubsection{HAD versus manual driving}

A driving simulator study by Barnard and Lai (2010) found that drivers in a HAD condition were less likely to spot the sudden appearance of objects (sheep, police cars) at the side of the road, as compared to manual driving (63\% vs. $77 \%$ of 6 participants, averaged across all trials). In this study, participants were instructed to perform visual secondary tasks which meant that they had to take their eyes off the road.

A study by Davis et al. (2008) evaluated automated convoy following in a real military vehicle where participants were instructed to spot as many targets as possible. Targets included large barrels, cones, and trash cans. Participants indicated the detection of a target by pressing a button on the steering wheel as well as by verbally reporting the location and type of target detected. The participants $(N=12)$ detected more objects in the environment when driving in the automated platoon as compared to driving manually (47\% vs. 39\% of objects). A real-vehicle study by McDowell et al. (2008) found that military convoy drivers detected more green target silhouettes along either side of the road for HAD as compared to manual driving (sensitivity index $\left[d^{\prime}\right]=2.10$ vs. 1.85 ). These targets were also detected faster for HAD compared to manual driving (5.75 vs. 
7.45 s). In the study by McDowell et al., the participants used indirect vision, that is, driving and object-detection from screens on board the vehicle.

\subsubsection{Summary}

The empirical evidence shows that both ACC and HAD can result in improved situation awareness compared to manual driving. This appears to be the case if drivers are motivated or instructed to detect objects in the environment. However, if drivers are engaging in non-driving tasks, situation awareness actually deteriorates for HAD compared to manual driving.

\subsection{Situation awareness measured by voluntary uptake of tasks unrelated to driving}

\subsubsection{ACC versus manual driving}

As part of the EUROFOT field-operational test, videos of 416 real-driving events were annotated. The results showed that ACC drivers were about three times more likely to engage in secondary tasks (e.g., reading a map, looking at a passenger or at an object in the car) than manual drivers (Malta et al., 2012). Sayer, Mefford, Shirkey, and Lantz (2005) reported on another field operational test (the ACAS FOT) involving 66 drivers. These authors found that secondary tasks (e.g., conversation with passengers, grooming, cell phone activity) were equally likely for ACC driving and manual driving (19\% of the time for both conditions).

\subsubsection{HAD versus manual driving}

A simulator study by Carsten et al. (2012) found that drivers were more likely to use a DVD player during HAD than during ACC driving and manual driving (32.5\%, 4.0\%, \& 2.6\% of the time; $N=49$ for HAD and manual driving, but $N=25$ for ACC). The corresponding percentages of radio use were $54.1 \%, 68.0 \%$, and $41.4 \%$, respectively. HAD drivers were also inclined to read a magazine (9\% of time) whereas this behaviour did not occur during ACC and manual driving. Carsten et al. (2012) reported that the total number of instances of eating was 12 during manual driving versus 47 during HAD.

A test-track study by Llaneras et al. (2013) also found large increases in non-driving activities for HAD. Ten of 12 participants reached a rear compartment, 8 of 12 participants were observed to eat, and 6 of 12 participants were texting or emailing in a 1.5 to 2 -h drive in a highly automated car. Only 1 or 2 of 12 participants engaged in these behaviours during a 45-min to 1-h drive with ACC engaged. Listening to music occurred for both HAD and ACC (11 of 12 drivers in both groups).

Omae, Hashimoto, Sugamoto, and Shimizu (2005) let 30 drivers experience a ride in a real highly automated vehicle on a test track. Even though the participants were told that the automation could display steering failures that required manual intervention, 8 participants fell asleep during the drives. Some participants started reading, operating their mobile phone, crossing their legs, or leaning out of the window. The drivers stated that they engaged in these behaviours because the task was boring and they had nothing to do. Levitan and Bloomfield (1996) investigated what drivers $(N=36)$ do when they are traveling under automated control in a driving simulator. They observed that drivers were inclined to interact with an available laptop computer (about 15 times per drive).

\subsubsection{Summary}

HAD drivers are strongly inclined to engage in non-driving tasks, such as watching a DVD or even sleeping. ACC drivers are less inclined to engage in non-driving tasks than HAD drivers.

\subsection{Situation awareness measured with critical events}

\subsubsection{ACC versus manual driving}

A number of studies have found that ACC drivers respond slowly to critical events compared to manual drivers. A testtrack study by Rudin-Brown and Parker (2004) found that participants driving with ACC took longer to react to a lead vehicle's brake lights than participants driving manually (2.7 vs. $2.0 \mathrm{~s} ; N=17$ ). A driving simulator study by Van der Hulst et al. (1996) found lower time-to-collision values for ACC driving as compared to manual driving in various critical highway scenarios (quantitative data not reported; $N=20$ per group). Stanton et al. (1997) found that 4 of 12 participants collided with the lead car when the ACC inadvertently accelerated. Elsewhere, Stanton et al. (2001) reported more rear-end collisions with a hard-braking lead vehicle for ACC drivers compared to manual drivers ( 4 vs. 17 out of 20 drivers). In both studies by Stanton and colleagues, the participants received no warning signal prior to the ACC failure. A simulator study by Lee et al. (2007) found that drivers' braking or steering reaction time to a sudden speed reduction of a lead car was longer during ACC driving with a failing brake system as compared to manual driving ( 1.59 vs. $0.81 \mathrm{~s} ; N=20)$. A simulator study by Kassner et al. (2011) found that ACC drivers had a longer brake reaction time to a traffic light switching to red than manual drivers in a scenario where the lead vehicle violated the red light (1.43 vs. $0.82 \mathrm{~s} ; N=12$ ). A study by Larsson, Kircher, and Hultgren (2014) in a high-fidelity driving simulator found longer brake reaction times to a cut-in vehicle for ACC driving than for manual driving ( 3.21 vs. $1.34 \mathrm{~s} ; N=28$ vs. $N=13$, not all drivers reacted by braking).

As reported above, ACC drivers sometimes react slowly in critical event scenarios. However, several studies have reported equivalent or slightly faster response times for ACC as compared to manual driving. In a simulator study by Nilsson (1995), 4 of 10 participants in the ACC group and 1 of 10 participants in the manual group crashed their car into a stationary queue of vehicles, a non-significant difference. The ACC system did not detect the stationary vehicles and provided no warning. The 
participants in both the ACC and manual groups appropriately avoided accidents in two other types of critical scenarios that required hard braking, with slightly faster brake reaction times for ACC than for manual driving (1.11 vs. $1.17 \mathrm{~s}$ in scenario where a lead vehicle suddenly pulled out, and 1.33 vs. $1.49 \mathrm{~s}$ in hard-braking lead vehicle scenario with acoustic warning when the ACC's deceleration limit was exceeded). Lee, McGehee, Brown, and Marshall (2006) evaluated the responses of 60 drivers to various scenarios including a slow lead vehicle, a braking lead vehicle, and unnecessary decelerations by the ACC system. The results indicated that reaction times and minimum time-to-collision values were dependent on the type of scenario and the modality of the warning stimulus. Overall, the results of Lee et al. (2006) show that drivers were able to effectively resume control when warned that ACC deceleration limits had been exceeded. Martens et al. (2008) found that manual drivers were less likely to brake for a yellow light than ACC drivers (58\% of manual drivers, $13 \%$ of ACC drivers, $30 \%$ of HAD drivers run the red light; $N=43$ ). Finally, a driving simulator study by Kondo et al. (1999) found no significant differences between ACC and manual driving regarding the mean brake response times to four different critical events that required hard braking $(N=11)$.

\subsubsection{HAD versus manual/ACC driving}

Various driving simulator studies indicate that HAD evokes slow responses times and an elevated risk of collisions compared to manual and ACC driving. A study in a high-fidelity simulator by Strand, Nilsson, Karlsson, and Nilsson (2014) found that HAD drivers had more collisions with a hard-braking lead vehicle than ACC drivers (43\% vs. $22 \%, N=18$ per group; note that collisions did not actually materialize, but participants passed a 'point of no return'). In the study by Strand et al. (2013), no warning upon automation failure was provided. Another study in a high-fidelity simulator found longer take-over times for HAD compared to manual driving (2.37 vs. $1.85 \mathrm{~s}, N=48$; Radlmayr, Gold, \& Bengler, in press). The number of collisions seemed comparable for HAD vs. manual driving ( 7 vs. 5 out of 48 participants collided per session). Participants were distracted with a visual or cognitive task, but were pre-warned through a high-pitch tone in combination with an icon change on the instrument panel (Radlmayr et al., in press). Merat and Jamson (2009) found that drivers of a highly automated car took $2.5 \mathrm{~s}$ longer to press the brakes in response to a red traffic light than people driving manually. The authors also observed slow brake response times with respect to emerging and oncoming vehicles for HAD as compared to manual driving. Flemisch et al. (2008) found that none of the 5 participants kept the car on the road after HAD system failed $2 \mathrm{~s}$ before entering a curve. In this study an acoustic warning was provided at the moment of failure. Flemisch et al. (2011) found that HAD yielded lower time to collision values with a lead vehicle that braked hard than manual driving $(2.8 \mathrm{~s}$ vs. $4.0 \mathrm{~s}, N=6)$. In this study, a warning signal provided, but quite late, between 3.0 and $4.1 \mathrm{~s}$ prior to collision. De Waard et al. (1999), found that 10 out of 20 participants did not press the brake pedal when another car cut-in only $0.1 \mathrm{~m}$ ahead of the participant's vehicle. Schermers et al. (2004) found that drivers of a highly automated truck were less likely to change lanes than manual drivers after a lead vehicle braked hard on the verge of the longitudinal control capabilities of the automated system (17\% vs. $34 \%$ out of the number of events where the lead vehicle unexpectedly braked hard; $N=24$ ). Damböck et al. (2013) found longer reaction times for HAD compared to manual driving in a scenario where the lead vehicle braked hard (with flashing rear lights) with the longitudinal controller failing at the same moment ( $1.60 \mathrm{vs} .0 .85 \mathrm{~s}, N=18)$ and in a scenario where a wild animal ran onto the road, undetected by the sensors ( $1.51 \mathrm{vs}$. $0.94 \mathrm{~s}, N=13$ ). In the study by Damböck et al. (2013), reaction time was defined as the time from first glance towards the hazard to the moment of pressing the brake pedal. Omae et al. (2005) let 30 persons in a real automated car experience a sudden rotation of the steering wheel with 270 deg/s while driving at low speed (between 10 and $15 \mathrm{~km} / \mathrm{h}$ ). The drivers' median response time was about $1 \mathrm{~s}$, but some drivers took more than $5 \mathrm{~s}$ to respond, especially if the automation failure occurred after $1 \mathrm{~h}$ of driving.

There are various counterexamples showing that HAD yields critical event behaviours that are comparable to manual driving. Kircher, Larsson, and Hultgren (2014) studied how manual, ACC, and HAD drivers $(N=29)$ respond to various types of critical event scenarios (broken down car event, curve event, exit event) in a driving simulator. The drivers' behaviour turned out to highly depend on the type of scenario and the automation capabilities. In short, the results showed that drivers behaved intelligibly, by resuming control if the automation was likely to reach its functional limitations, and by not resuming control when the automation was likely to deal with the situation. Martens et al. (2008) found no statistically significant difference between manual, ACC, and HAD for a critical event where a car pulled out from a parking space, although the drivers in the highly automated condition experienced a relatively short time headway when having to brake for a traffic jam (3.0, 2.8, and $2.2 \mathrm{~s}$ for manual, ACC, and HAD, respectively). Merat et al. (2012) found that the proportion of drivers changing lane before a traffic cone was about the same during HAD and manual driving ( $41 \mathrm{vs.} 42$ out of 50 drivers when not performing a cognitive secondary task, and 36 vs. 32 out of 50 drivers when performing a cognitive task). Gold, Damböck, Lorenz, and Bengler (2013) showed that inattentive drivers of a highly automated car in a simulator properly avoided a stationary object when they had received an auditory warning (i.e., a takeover request) 5 or $7 \mathrm{~s}$ in advance. For the shorter take-over request time of $5 \mathrm{~s}$, the drivers were less likely to gaze into the mirrors and over the shoulders, and were more likely to brake rather than to steer around the object without braking. Another simulator study by Young (2000) found no differences between ACC and HAD regarding the number of drivers who responded to the automation failure occurring without salient warning at the same time as the lead car started braking ( 27 of 44 participants responded to the ACC failure, and 25 of 44 participants responded to the HAD failure). In Lank, Haberstroh, and Wille (2011), truck drivers experienced a HAD system in a simulator. No statistically significant difference was found between manual and HAD regarding the drivers' reaction time to an unexpected deceleration of the leading vehicle without brake lights. 


\subsubsection{Summary}

A wealth of evidence shows that HAD and ACC evoke long response times and an elevated rate of (near-) collisions in critical events as compared to manual driving. However, there are counterexamples, where drivers successfully avoid collision in critical event scenarios. Drivers' response times appear to be moderated by whether the driver is pre-warned as well as by the type of scenario. Essentially, if the automation fails unexpectedly with very little time for the human to respond, then almost all drivers crash (cf. Flemisch et al., 2008), but if drivers receive a timely warning then almost all drivers will safely avoid collision (cf. Gold et al., 2013).

\section{Discussion}

This review compared workload and situation awareness between manual driving, driving with ACC, and HAD. Our metaanalysis showed that ACC contributes to a small reduction of self-reported workload and a small performance improvement on self-paced in-vehicle display tasks as compared to manual driving. In comparison, HAD results in a large reduction of selfreported workload and a large improvement of performance on self-paced in-vehicle display tasks as compared to manual driving. Overall, our review provides strong evidence that automation reduces workload, and that there is a crucial difference between ACC driving and HAD from a Human Factors point of view.

Measurements of drivers' heart rate suggest that HAD yields lower workload than driving with ACC which in turn yields lower workload than manual driving (e.g., Carsten et al., 2012). However, a number of studies have found no statistically significant differences, possibly because of large individual differences in heart rate and because the true effect size is small. In addition, many of the reviewed studies were not randomized, but started out with manual driving followed by automated driving. Considering that heart rate exhibits strong time-on-task effects (presumably because drivers acclimatize to the experimental situation), we conclude that the current evidence regarding the effect of automation on heart rate is rather frail. An insightful literature review by Desmond (1997) points to further methodological challenges of measuring heart rate, such as circadian trends and the fact that driver's movement and muscle tension may confound the measurement. The main advantage of physiological measurements is that they are performed during driving and can therefore be used to infer timeon-task effects (e.g., Vollrath et al., 2010) and workload changes while a critical event unfolds (Collet, Petit, Champely, \& Dittmar, 2003; De Waard et al., 1999). De Waard et al. (1999), for example, found a drop of heart rate during a critical HAD event, while the participant was leading a platoon. During this critical event, another vehicle cut-in very close in front of the participant's vehicle. The mean heart rate was 73.4 beats/min prior to the critical event, and reached a minimum of 71.9 beats/min during the critical event.

Effect sizes were also small for non-visual tasks: no statistically significant effects were observed between ACC/HAD and manual driving, presumably because these types of secondary tasks can be performed without having to take the eyes of the road. However, the number of studies in this category was small, and studies may have been underpowered to detect the small effects which might exist.

Several studies have found that ACC/HAD drivers react faster to artificial visual stimuli than manual drivers. However, Cha (2003) found longer reaction times to visual stimuli for HAD as compared to manual driving, possibly because of driver drowsiness. The results of our literature review suggest that when drivers are engaged in the secondary task, ACC and HAD might help them to achieve a faster reaction time than what is achieved during manual driving. When drivers are drowsy because of a monotonous automated drive, they respond more slowly than manual drivers.

Results for situation awareness vary: Some studies have shown that ACC and HAD result in improved object detection compared to manual driving, whereas other studies have found that ACC and HAD give rise to a reduction of situation awareness. These divergent results can be explained with the driver model shown in Fig. 1. During manual or ACC driving the human should visually sample the road and turn the steering wheel on a semi-continuous basis. In contrast, during HAD, the human does not have to attend to the roadway when the automation is functioning reliably, but can engage in diverse types of tasks: an in-vehicle visual task (task 3), observing objects in the environment (task 6), or tasks that are unrelated to driving (task 7). When the driver of a highly-automated car decides to allocate attention to objects in the environment (task 6), a 'super situation awareness' is attained, meaning that situation awareness scores are better than during manual driving. When HAD drivers engage in tasks that are unrelated to driving, such as reading, reaching a rear compartment, or sleeping (task 7), situation awareness scores are actually low compared to manual driving, and responses will be slow during a critical event that requires human intervention. Our review of eye-movement data concurs that HAD drivers are less likely to gaze at the road than manual drivers.

Our review of drivers' behaviour in critical event scenarios indicates that accidents are likely to happen if drivers are not attending to the road and are not prepared for intervention. The results of our review clearly suggest that a proper feedback system could alleviate much of the concerns of low workload and low situation awareness of HAD. Gold et al. (2013), for example, showed that providing a takeover request (i.e., a simple audio-visual warning) 5 to $7 \mathrm{~s}$ in advance ensures that drivers of a highly automated car avoided a stationary object, even if they were not attending to the road prior to the takeover request. Based on a series of experimental studies, Levitan, Golembiewski, and Bloomfield (1998) concluded that drivers need to perform a so-called readiness test to demonstrate alertness, before manual control is resumed after having travelled under HAD. An on-road study by Stanton, Dunoyer, and Leatherland (2011) and a driving simulator study by Seppelt and Lee (2007) indicated that a visual display providing continuous information about ACC functionality has the potential to improve 
driver's situation awareness. Adaptive automation approaches are feasible too; some researchers have successfully tested a visual attention monitor that automatically provides feedback when the driver engages in a non-driving task (Flemisch et al., 2011; Merat, Jamson, Lai, Daly, \& Carsten, 2014; Salinger, 2012). These findings are in line with Norman (1990) who argued that lack of feedback about automation status is an important cause of automation-induced accidents.

\subsection{Limitations and moderator variables}

Almost all studies included in the meta-analysis have been conducted in simulators (Table 1). Workload is typically higher in real cars compared to matched experiments in driving simulators (Stanton et al., 2001; Sterling et al., 2007). However, this effect does not generalize across different driving tasks. For example, a study by Nowakowski, O'Connell, Shladover, and Cody (2010) found low self-reported workload in a real car (34\% for manual driving and $14 \%$ for ACC), probably because the participants were commuting to their work on a familiar route. Krause, Yilmaz, and Bengler (2014) also found a low workload of $14 \%$ on the NASA TLX for driving in a real car on a rural road, considerably lower than the workload for simulator driving (25\%). Participants are usually not accustomed to driving in simulators, and workload scores are likely to drop after an acclimatization period of some days or weeks. Farber (1999) argued that a single drive in a highly automated car will not yield results that are representative of real driving.

Neale and Dingus (1998) and Farber (1999) stated that simulators do not provide an accurate representation of the phenomenology of real automated driving. Table 1 indicated that two-thirds of the experiments have been conducted in fixed-base (i.e., low or medium fidelity) driving simulators, which may be problematic in terms of validity. For example, one on-road study has found that drivers valued the deceleration cue that could be felt when the ACC began to slow down, as it drew their attention to an arising conflict (Fancher et al., 1998). A test-track study by Bender, Landau, and Bruder (2006) found that in $88 \%$ of the automatic braking interventions, participants inadvertently pressed down the gas pedal due to the inertia forces caused by the deceleration of the vehicle. Such motion effects are probably not reproducible with fixed-base simulators. The luminance of a simulator is of influence on the experimental outcomes as well. Levitan and Bloomfield (1996) reasoned that the dark illumination of the simulator cabin may have discouraged reading activities during HAD. The numerous phenomena that can be evaluated introduces the question whether future experiments should focus on basic psychological research (using low fidelity simulators) or on ecologically-valid idiosyncrasies (using high fidelity simulators). Neubauer, Matthews, Saxby, and Langheim (2010) argued that desktop-based driving simulators provide valid results regarding subjective stress, fatigue, loss of task engagement, and drivers' response to critical events. In an exploratory moderator analysis, we found that self-reported workload did not correlate significantly with simulator fidelity (Spearman rank correlation $=-.29$ across 29 studies; 1 = low fidelity simulator; 2 = medium fidelity simulator; $3=$ high fidelity simulator).

Table 1 showed that two-thirds of the included studies were of a within-subject design. Within-subjects studies are prone to carry-over effects from automated to manual driving or vice versa. For example, critical events that required manual intervention may have influenced the driver's workload and situation awareness in the subsequent driving trial. Our literature review indicated the importance of proper randomization/counterbalancing of experimental conditions, as secondary tasks and responses to critical events are clearly influenced by learning effects. Nirschl and Kopf (1997), for example, measured drivers' $(N=12)$ reaction times to a light on the dashboard of a real car. A time-on-task effect was observed as the mean reaction time was $2.90 \mathrm{~s}$ in the first drive, and $2.54 \mathrm{~s}$ in the subsequent drive. Young (2000) found a learning effect in a critical event scenario that required a braking intervention, with 16 of 44 participants responding in trial 1, and 36 of 44 participants responding in trial 2. A survey among ACC users showed that the longer drivers own the system, the more aware of its limitations they become (Larsson, 2012). Experimenter blinding or information disclosure may have had an effect on workload and situation awareness. Beggiato and Krems (2013) found that ACC failures do not have a negative effect on ratings of trust and acceptance if the possible occurrence of failures is told beforehand. Llaneras et al. (2013) and Levitan and Bloomfield (1996) stated that the mere presence and behaviour of the experimenter on the passenger seat may have had an effect on the uptake of non-driving in their studies.

The duration of the driving sessions is another critical moderator variable. In a correlational analysis, we found no statistically significant correlation between the duration of the experiment and self-reported workload. However, all experiments were fairly short, averaging at $1.0 \mathrm{~h}$ only, with a maximum of $3 \mathrm{~h}$ (see Table 1 ). Prolonged driving in one stint may lead to increased workload if the driver is required to remain attentive, as vigilance tasks induce workload, stress, and frustration (Szalma et al., 2004; Warm, Parasuraman, \& Matthews, 2008). However, if drivers have little to do, they might lose motivation and become bored (Desmond et al., 1998). Saxby et al. (2013) found that self-reported workload was the same for HAD and manual driving for a 10 min driving session, but was considerably lower for HAD compared to manual driving after 50 min of driving, because workload for manual driving increased whereas workload for HAD remained approximately constant with driving time.

Sears (1986) stated that many psychological research findings are poorly generalizable, because the research has been conducted with university students. In an exploratory moderator analysis, we found a statistically significant Spearman correlation (.67, $p=.00013$ ) between mean age and simulator fidelity. This can be explained by the fact that much of the fundamental psychological research is done in low fidelity simulators at universities, whereas research institutes having high fidelity driving simulators tend to recruit their own employees or drivers from a database of volunteers. Young and Stanton (2007) showed that novice drivers perform poorly at secondary tasks during manual driving compared to expert drivers, and that HAD therefore has stronger effects among novices than among experts (Young \& Stanton, 2007). A simulator 
study by Piccinini et al. (2013) found that drivers who had prior experience with using ACC reported lower workload (than drivers who did not have prior experience with ACC (8\% vs. 17\% on the NASA TLX). Larsson et al. (2014) found that drivers who had prior experience with ACC had shorter reaction times to a cut-in vehicle than drivers without ACC experience, whereas Petermann-Stock, Hackenberg, Muhr and Mergl (2013) found no significant differences in automation take-over times between 25-35 year old drivers versus 50-70 year old drivers. Goodall (2014a) argued that future generations, which will have grown up using automated vehicles, will be more likely to rely on automation than today's drivers. Males select shorter time-gaps than females when using ACC, whereas women are more likely to engage in certain types of non-driving tasks such as conversing with passengers (Nowakowski et al., 2010; Oberholtzer et al., 2007). Neubauer, Matthews, Saxby, and Langheim (2011) found that fatigued drivers were more likely to enable HAD. More generally, it is known that there are large individual differences in automation use and trust in automation (Parasuraman \& Riley, 1997; Rajaonah, Tricot, Anceaux, \& Millot, 2008). In summary, individual differences in age, gender, and driving experience may explain a large share of the variance of the observed workload and situation awareness scores.

The studies included in Table 1 were conducted at different driving speeds. For example, in Brook-Carter et al. (2002), participants drove in an urban environment with a mean speed of about $35 \mathrm{~km} / \mathrm{h}$ whereas in Vollrath, Schleicher, and Gelau (2011; see also 2010) participants drove on a simulated German Autobahn at mean speeds up to $160 \mathrm{~km} / \mathrm{h}$. It is known that speed of the vehicle is monotonically related to self-reported workload (Fuller, 2005). However, this relationship does not necessarily hold across different driving environments. For example, Hoedemaeker found that drivers' self-reported workload was lower on the motorway than on the rural road, even though the mean speed was higher on the motorway. Real-world studies by Sterling et al. (2007) and McDowell et al. (2008) showed that HAD can contribute to elevated workload if the vehicle drives faster than the speeds that manual drivers choose. Young and Stanton (2004) found that not the mean speed, but the variability of lead car speed, has an impact on workload. They explained that using a constant-speed lead vehicle is not a fair test of the workload-reduction potential of ACC, because manually following a lead car having a constant speed is an easy task.

Headway is another important moderator variable. Drivers generally feel that close headways (e.g., $<0.5 \mathrm{~s}$ ) induce an elevated sense of workload, risk, and discomfort (Bloomfield, Christensen, Carroll, \& Watson, 1996; De Vos, Theeuwes, Hoekstra, \& Coëmet, 1997; De Waard et al., 1999; Larburu, Sanchez, \& Rodriguez, 2010; Levitan et al., 1998; Lewis-Evans, De Waard, \& Brookhuis, 2010; Saffarian, De Winter, \& Happee, 2012; Siebert, Oehl, \& Pfister, 2014; Watanabe, Kishimoto, Hayafune, Yamada, \& Maede, 1995), not to mention the increased crash risk (Lewis-Evans et al., 2010; Lin, Hwang, \& Green, 2009; Lin, Hwang, Su, \& Chen, 2008; Van den Beukel \& Van der Voort, 2013). In some studies, participants drove with extremely close headways of 0.25 s or less (Cha, 2003; De Waard et al., 1999). However, in De Waard et al. (1999), self-reported workload during HAD was actually very low (11\%), presumably because the drivers were not offered a secondary task, and had nothing to do.

Human Factors of automated driving cannot be studied without considering the car's technological capabilities. Suppose an automated car would have perfect sensors, software, and actuators, then it is almost obvious that the human should be excluded from the control loop (Inagaki \& Sheridan, 2012). In other words, the negative effects of ACC and HAD during critical events (Section 3.9) do not at all imply that ACC/HAD is unsafe, because these critical events will not occur if the automation is reliable. An on-road study by Davis et al. (2008) showed that their (partially) automated car outperformed human drivers: the automation responded to unanticipated events on average about $0.08 \mathrm{~s}$ faster than manual drivers did, and resulted in $8.5 \mathrm{~m}$ shorter stopping distances (Davis et al., 2008). Lee et al. (2006) found that ACC actually helped to respond to speed changes of a lead car, as long as the deceleration limits of the ACC system were not reached. Marcus (2012) stated that in a few decades automated driving will be so reliable that humans will not be legally allowed to drive (Note that Marcus' prediction is in opposition to the Vienna Convention on Road Traffic, currently signed by 70 countries, stating that "every driver shall at all times be able to control his vehicle or to guide his animals", United Nations, 1968, p. 11). However, now suppose that an automated car has a strong tendency to fail in time-critical situations, then manual driving will be safer than automated driving. DeMers et al. (1995) performed a computer simulation of the effect of 'hard-over' steering failures (i. e., steering wheel was turned with $40 \mathrm{deg} / \mathrm{s}$ ), and concluded that humans are unable to prevent an accident if this would happen in a real car.

The automation capabilities and the type of critical event both have an effect on the driver's behaviour. Nilsson, Strand, Falcone, and Vinter (2013) studied how drivers respond to various types of ACC failures, namely unwanted acceleration, complete lack of deceleration, partial lack of deceleration, and speed limit violation. The partial lack of deceleration turned out to be the most dangerous, leading to a collision with the lead car in 43\% of the cases. In the study by Nilsson et al. (2013), drivers were given no warnings or other indication of the failure. Studies by Gold, Lorenz, and Bengler (2014) and Radlmayr et al. (in press) concur that drivers' response times depend on the type of critical event, as well as on the type of distraction (i.e., cognitive vs. visual distraction). A speed-limit violation scenario is strictly not a critical event, since no imminent response is required by the driver. However, there are indications that HAD and ACC evoke complacent behaviours in this scenario too. For example, Merat and Jamson (2009) found that 7 of 39 drivers did not disengage the HAD system, thereby allowing the vehicle to drive above the posted speed limit (data reported in Schieben, Temme, Köster, \& Flemisch, 2011). Damböck et al. (2013) found that only 9 of 24 participants consistently intervened (i.e., pressed the brakes or disabled the automation) in a traffic sign scenario, and for those who intervened, they did so on average $84 \mathrm{~m}$ later than during manual driving. Finally, Vollrath et al. (2011) found that ACC drivers took between 5 to $10 \mathrm{~s}$ longer to adjust their speed to changing speed limits than manual drivers. 
We used different scales for assessing self-reported workload. The TLX and RSME scales may not be readily comparable, as the TLX assesses workload across six items, whereas the RSME only assesses effort. The TLX includes a physical demand item, and it is perhaps obvious that physical demands and heart rate will be lower during HAD as compared to manual driving, as drivers do not have to move the steering wheel and pedals. The TLX also assesses frustration, and there are some indications that automation can evoke frustration, especially when the automation provides nuisance warnings (Kassner et al., 2011) or cannot be overruled (cf. Comte, 2000 for an intelligent speed adaptation study). For the TLX scales, self-reported workload was $46 \%, 41 \%$, and $24 \%$ for manual driving, ACC, and HAD, respectively. For the RSME scales, the corresponding self-reported workload was $35.0 \%, 27.7 \%$, and $17.3 \%$. Brook-Carter et al. (2002) used both the TLX and the RSME in the same experiment, and found that the mean workload across all conditions was 38.7\% for the TLX and $40.9 \%$ for the RSME. In other words, there are some indications that RSME scores are lower than TLX scores, but the relative differences among manual driving, ACC, and HAD is consistent across these two scales.

Summarizing, there are numerous sources of identifiable heterogeneity, and each experimental study is unique in various ways. Nonetheless, the results our meta-analysis (Figs. 2 and 3) are markedly robust, as in almost all studies HAD (and to a lesser extent ACC) gives rise to a reduction of workload as compared to manual driving.

\subsection{Remaining Human Factors questions}

Our review showed that drivers of a highly automated are inclined to pick up non-driving tasks. A major remaining Human Factors question then is whether this is desirable. According to one school of thought, drivers should not be required to vigilantly monitor the road. Jacoby and Schuster (1997) stated: "The driver cannot be relied upon to act as a monitor if moment-to-moment vehicle control is taken away" (p. 612). Farber (1999) pointed out: "Can drivers free of routine driving duties be relied upon to perform this function? In my view the notion is simply preposterous" (p. 83). Omae et al. (2005) tested 30 drivers in a highly automated car on the road, and after the experiments asked whether they wanted to use automated driven vehicles if they were required to supervise the system. 23 of the 30 drivers answered 'no' to this question. The second school of thought argues that a human operator is vital in a highly automated system (Merat \& Lee, 2012; Nilsson, 2005) and that driver of a highly automated car should not have a passive role (De Waard et al., 1999). Developers of an automated driving system that could drive for hours on a highway argued that concentration is constantly required despite the monotonous situation (Lank et al., 2011). A parallel of the second school of thought may be found in aviation. Although aircraft are able to fly automatically, the crew is busy with programming and monitoring, and occasionally reclaim manual control because automation is not always reliable and does not function in all circumstances (Sheridan, 2004). There are, however, important differences between aviation and car driving; the latter features more dynamic interactions with other vehicles, whereas the former is more highly proceduralized.

Our review dealt with ACC and HAD only. One type of automation not included in our review is automated steering. Automated steering and ACC are both driving assistance systems according to the BASt definition, with the critical difference that in automated steering the lateral instead of the longitudinal motion of the car is automated. However, from a Human Factors viewpoint, ACC and automated steering are clearly different, as automated steering yields stronger workload reductions with respect to manual driving than ACC does. A simulator study by Young and Stanton (2007) found that participants $(N=114)$ completed substantially more visual secondary tasks correctly under automated steering than under ACC (143 vs. 85). In another simulator study, Carsten et al. (2012) found that participants spent a larger proportion of their time using a DVD player when steering was automated than when using ACC (18.0\% vs. 4.0\%). Further discussion on the Human Factors differences between ACC and automated steering is provided by Young and Stanton (2002), Young (2000), and Carsten et al. (2012).

A research question requiring further attention is how to perform transitions from manual to automated control, or vice versa. Thompson and Tönnis (2007) argued that adjusting the automation status is itself a secondary task that should not induce too much extra workload. In Jamson et al. (2013), moving the steering wheel by more than 3 degrees deactivated the HAD system, which means that the driver should release his/her hands from the steering wheel when the automation is active. However, Strand et al. (2014) actually instructed the HAD drivers to keep their hands on the steering wheel, in an attempt to keep them mentally and physically involved in the driving task. Damböck et al. (2013) investigated both the hand-off and hand-on method, and found that the hands-off method yielded slower reaction times in critical event scenarios. Using buttons for transitioning between manual and automated driving is another common solution in dual-mode driving (Schieben et al., 2008). A driving simulator study by Levitan et al. (1998) indicated that in a transition from automated to manual control, the driver should first take control of steering followed by speed or of steering and speed simultaneously. Participants did not prefer the speed-followed-by-steering method of transitioning.

Another Human Factors question not covered by the present review is whether automated driving results in adverse after-effects. There are some indications that after seeing or experiencing automated driving, drivers show poorer lane keeping performance, shorter headways, or delayed reaction times as compared to drivers who have not seen/experienced automated driving (Comte, 2000; Desmond et al., 1998; Eick \& Debus, 2005; Gouy, Diels, Reed, Stevens, \& Burnett, 2013; Gouy, Wiedemann, Stevens, Brunett, \& Reed, 2014; Levitan et al., 1998; Merat et al., 2014; Neubauer et al., 2012; Saxby et al., 2013; Skottke, Debus, Wang, \& Huestegge, in press; Wille et al., 2007). This type of behavioural research seems to be characterised by small effect sizes and interpretation problems. For example, Levitan et al. (1998) found better lane keeping performance during manual driving after a period of automated driving, as compared to before the automated 
driving. However, the drivers actually did poorer at maintaining a constant speed after automated travel than before it. This suggests that drivers merely reallocated their attention to different driving subtasks. Other research suggests that any aftereffects may be a straightforward consequence of the total time on task, whereby the manual group is more accustomed to manual driving than the group who drove using automation.

It is unclear how the general public feels about automated cars. An early survey study by Bekiaris, Petica, and Brookhuis (1997) found a definite rejection of automated driving. After experiencing HAD in a driving simulator, only 13 of 38 participants stated that they wished to have the system in their car, possibly because the system did not prevent incidents (Schieben et al., 2008). In Flemisch et al. (2011), people who just experienced a test ride in a simulator were asked how much they would like to drive such a highly automated vehicle if it would be available. Most of the participants were positively interested, and they particularly liked the increase of comfort and safety. However, some respondents did not like the idea of handing over control to automation. Indeed, social acceptance and the idea that automation will deprive people of personal control over their vehicles are possible concerns of automated driving (Howard \& Dai, 2014; Shladover, 1998).

It may take a number of decades before HAD will be ubiquitous. An early Delphi survey among experts predicted that fully automated driving will never reach a 50\% market share (Underwood, 1992). Michon (1993) argued that for a very long time to come, only humans will be able to handle the complex information processing demands of car driving. Manufacturers have always been hesitant to adopt new technologies, such as seat belts, air bags, and cruise control (Beiker, 2012; Seiniger, Westhoff, Fahrenkrog, \& Zlocki, 2011). A mock trial described by Noy et al. (2000) showed that Human Factors knowledge regarding human reaction times, vigilance, and trust, is important in reaching appropriate legal decisions. Finally, solving ethical problems of automated driving, such as computer hacking (Smith, 2013), privacy (Glancy, 2012), the use of automated cars for military operations (Quintana, 2008), and decision making during unavoidable crashes (Goodall, 2014a, 2014b), all require advances in Human Factors knowledge.

\section{Acknowledgement}

The authors are involved in the Marie Curie Initial Training Network (ITN) HFAuto - Human Factors of Automated Driving (PITN-GA-2013-605817).

\section{Appendix A. Supplementary data}

Supplementary data associated with this article can be found, in the online version, at http://dx.doi.org/10.1016/j. trf.2014.06.016.

\section{References}

References marked with an asterisk indicate studies included in the meta analysis.

Acura (2014). http://www.acura.ca/mdx/technology. Retrieved from http://www.acura.ca/mdx/technology.

Adam, E. V. (1993). Fighter cockpits of the future. In Proceedings of the 12th IEEE/AIAA Digital Avionics Systems Conference, Fort Worth, TX (pp. 318-323). http://dx.doi.org/10.1109/dasc.1993.283529.

Alecandri, E., \& Moyer, M. J. (1992). Human factors and the automated highway system. In Proceedings of the Human Factors Society Annual Meeting, Vol. 36 (pp. 1064-1067).

Barfield, W., \& Dingus, T. A. (1998). Human factors in intelligent transportation systems. Mahwah, NJ: Lawrence Erlbaum Associates Inc.

Barnard, Y., \& Lai, F. (2010). Spotting sheep in Yorkshire: Using eye-tracking for studying situation awareness in a driving simulator. In D. de Waard, A. Axelsson, M. Berglund, B. Peters, \& C. Weikert (Eds.), Human Factors: A system view of human, technology, and organisation (pp. 249-261). Maastricht, The Netherlands: Shaker Publishing.

Beach, A. (1870). The pneumatic tunnel under Broadway. New York Scientific American, 22, 154-156.

Beggiato, M., \& Krems, J. F. (2013). The evolution of mental model, trust and acceptance of adaptive cruise control in relation to initial information. Transportation Research Part F: Traffic Psychology and Behaviour, 18, 47-57. http://dx.doi.org/10.1016/j.trf.2012.12.006.

Beiker, S. A. (2012). Legal aspects of autonomous driving: The need for a legal infrastructure that permits autonomous driving in public to maximize safety and consumer benefit. Santa Clara Law Review, 52, 1145-1561.

Bekiaris, E., Petica, S., \& Brookhuis, K. (1997). Driver needs and public acceptance regarding telematic in-vehicle emergency control aids. Paper presented at Mobility for Everyone. In 4th World congress on intelligent transport systems, Berlin, Germany (Paper No. 2077).

Bender, E., Landau, K., \& Bruder, R. (2006). Driver reactions in response to automatic obstacle avoiding manoeuvres. In Proceedings of the 16th World Congress on Ergonomics. Maastricht, The Netherlands: Elsevier.

*Bjørkli, C. A., Jenssen, G. D., Moen, T., \& Vaa, T. (2003). Adaptive Cruise Control (ACC) and driver performance: Effects on objective and subjective measures. Paper presented at the 10th world congress on intelligent transportation systems, Madrid, Spain (pp. 16-20).

Bloomfield, J. R., Christensen, J. M., Carroll, S. A., \& Watson, G. S. (1996). The driver's response to decreasing vehicle separations during transitions into the automated lane (Technical Report No. FHWA-RD-95-107). Washington, DC: Federal Highway Administration.

BMW (2013). BMW ConnectedDrive from A to Z [Company website]. Retrieved from http://www.bmw.com/com/en/insights/technology/connecteddrive/ 2013/a_to_z/index.html.

Bond, C. F., Wiitala, W. L., \& Richard, F. D. (2003). Meta-analysis of raw mean differences. Psychological Methods, 8, 406-418. http://dx.doi.org/10.1037/1082989x.8.4.406.

*Brook-Carter, N., Parkes, A. M., Burns, P., \& Kersloot, T. (2002). An investigation of the effect of an urban adaptive cruise control (ACC) system on driving performance. In Proceedings of the 9th World Congress on Intelligent Transport Systems. Chicago, IL.

Brookhuis, K. A., Van Driel, C. J., Hof, T., Van Arem, B., \& Hoedemaeker, M. (2009). Driving with a congestion assistant; mental workload and acceptance. Applied Ergonomics, 40, 1019-1025. http://dx.doi.org/10.1016/j.apergo.2008.06.010.

Carsten, O. (2004). Driver assistance systems: Safe or unsafe. In T. Rothengatter \& R. D. Huguenin (Eds.), Traffic and transport psychology (pp. 339-345). Amsterdam, The Netherlands: Elsevier Ltd. 
Carsten, O., Lai, F. C., Barnard, Y., Jamson, A. H., \& Merat, N. (2012). Control task substitution in semiautomated driving. Does it matter what aspects are automated? Human Factors: The Journal of the Human Factors and Ergonomics Society, 54, 747-761. http://dx.doi.org/10.1177/0018720812460246.

Cha, D. (2003). Driver workload comparisons among road sections of automated highway systems. In Proceedings of the Society of Automotive Engineers 2003 World Congress, Detroit, MI (Technical Paper 2003-01-0119). http://dx.doi.org/10.4271/2003-01-0119.

Cho, J. H., Nam, H. K., \& Lee, W. S. (2006). Driver behavior with adaptive cruise control. International Journal of Automotive Technology, 7, 603-608.

Collet, C., Petit, C., Champely, S., \& Dittmar, A. (2003). Assessing workload through physiological measurements in bus drivers using an automated system during docking. Human Factors: The Journal of the Human Factors and Ergonomics Society, 45, 539-548. http://dx.doi.org/10.1518/hfes.45.4.539.27082.

Comte, S. L. (2000). New systems: New behaviour? Transportation Research Part F: Traffic Psychology and Behaviour, 3, 95-111. http://dx.doi.org/10.1016/ s1369-8478(00)00019-X.

Daimler (2013). DISTRONIC PLUS: Warns and assists the driver [Company website]. Retrieved from http://www.daimler.com/dccom/0-5-1210218-11210321-1-0-0-1210228-0-0-135-0-0-0-0-0-0-0-0.html.

${ }^{*}$ Damböck, D., Weißgerber, T., Kienle, M., \& Bengler, K. (2013). Requirements for cooperative vehicle guidance. In Proceedings of the 16th International IEEE Annual Conference on Intelligent Transportation Systems, The Hague, The Netherlands (pp. 1656-1661). http://dx.doi.org/10.1109/itsc.2013.6728467.

Davis, J., Animashaun, A., Schoenherr, E., \& McDowell, K. (2008). Evaluation of semi-autonomous convoy driving. Journal of Field Robotics, 25 , 880-897. http://dx.doi.org/10.1002/rob.20263.

*De Waard, D., Van der Hulst, M., Hoedemaeker, M., \& Brookhuis, K. A. (1999). Driver behavior in an emergency situation in the Automated Highway System. Transportation Human Factors, 1, 67-82. http://dx.doi.org/10.1207/sthf0101_7.

Desmond, P. A. (1997). Fatigue and stress in driving performance (Doctoral dissertation). University of Dundee, UK.

*De Winter, J. C. F., Stanton, N. A., Price, J. S., \& Mistry, H. (2014). The frustrated driver: An overlooked dimension of driving automation. Unpublished manuscript.

De Winter, J. C. F., Zadpoor, A. A., \& Dodou, D. (2014). The expansion of Google Scholar versus Web of Science: A longitudinal study. Scientometrics, 98, 1547-1565. http://dx.doi.org/10.1007/s11192-013-1089-2.

De Vos, A. P., Theeuwes, J., Hoekstra, W., \& Coëmet, M. J. (1997). Behavioral aspects of Automated Vehicle Guidance (AVG): Relationship between headway and driver comfort. Transportation Research Record: Journal of the Transportation Research Board, 1573, 17-22. http://dx.doi.org/10.3141/1573-03.

DeMers, R. E., Meisner, J. W., Frazzini, R., Funk, H. B., Plocher, T., Krueze, F., Williston, R. B. (1995). Malfunction management activity area report for AHS health management precursor system analysis (Report No. FHWA-RD-95-047). Washington, DC: Federal Highway Administration.

Desmond, P. A., Hancock, P. A., \& Monette, J. (1998). Fatigue and automation-induced impairments in simulated driving performance. Transportation Research Board, 1628, 8-14. http://dx.doi.org/10.3141/1628-02.

Dozza, M. (2012). What factors influence drivers' response time for evasive maneuvers in real traffic? Accident Analysis \& Prevention, 58, 299-308. http://dx. doi.org/10.1016/j.aap.2012.06.003.

Dragutinovic, N., Brookhuis, K. A., Hagenzieker, M. P., \& Marchau, V. A. W. J. (2005). Behavioural effects of Advanced Cruise Control use - A meta-analytic approach. European Journal of Transport and Infrastructure Research, 5, 267-280.

Eick, E. M., \& Debus, G. (2005). Adaptation effects in an automated car following scenario. In G. Underwood (Ed.), Traffic and transport psychology: Theory and application (pp. 243-255). Amsterdam, The Netherlands: Elsevier Ltd.

Endsley, M. R. (1988). Design and evaluation for situation awareness enhancement. In Proceedings of the Human Factors and Ergonomics Society Annual Meeting, Vol. 32 (pp. 97-101)

Fancher, P., Ervin, R., Sayer, J., Hagan, M., Bogard, S., Bareket, Z., Haugan, J. (1998). Intelligent cruise control field operational test. Final report (Report No. DOT HS 808 849). Ann Arbor, MI: The University of Michigan, Transportation Research Institute.

Farber, E. I. (1999). Comments on "Driver behavior in an emergency situation in the Automated Highway System". Transportation Human Factors, 1, 83-85. http://dx.doi.org/10.1207/sthf0101_8.

Fenton, R. E. (1970). Automatic vehicle guidance and control-A state of the art survey. IEEE Transactions on Vehicular Technology, 19, 153-161. http://dx.doi. org/10.1109/t-vt.1970.23443.

Ferdinand, A. O., \& Menachemi, N. (2014). Associations between driving performance and engaging in secondary tasks: A systematic review. American Journal of Public Health, 104, e39-e48. http://dx.doi.org/10.2105/ajph.2013.301750.

Flach, J. M. (1995). Situation awareness: Proceed with caution. Human Factors: The Journal of the Human Factors and Ergonomics Society, 37, 149-157. http:// dx.doi.org/10.1518/001872095779049480.

Fleming, B. (2012). New automotive electronics technologies. IEEE Vehicular Technology Magazine, 7, 4-12. http://dx.doi.org/10.1109/mvt.2012.2218144.

*Flemisch, F. O., Kelsch, J., Löper, C., Schieben, A., Schindler, J., \& Heesen, M. (2008). Cooperative control and active interfaces for vehicle assistance and automation. Paper presented at FISITA World Automotive Congress, Munich, Germany (Paper No. F2008-02-045). Retrieved from http://elib-v3.dlr.de/ 57618/1/FISITA2008_DLR_FlemischEtAl_CooperativeControl.pdf.

*Flemisch, F., Kaussner, A., Petermann, I., Schieben, A., \& Schöming, N. (2011). HAVE-IT. Highly automated vehicles for intelligent transport. Validation of concept on optimum task repartition (Deliverable D.33.6). Regensburg, Germany: Continental Automotive GmbH.

Foley, J. P., Young, R., Angell, L., \& Domeyer, J. E. (2013). Towards operationalizing driver distraction. In Proceedings of the 7th International Symposium on Human Factors in Driver Assessment, Training, and Vehicle Design. Bolton Landing, NY (pp. 57-63). Retrieved from http://drivingassessment.uiowa.edu/ sites/default/files/DA2013/Papers/010_Foley_0.pdf.

Fotsch, P. M. (2001). The building of a superhighway: Future at the New York World's Fair. Cultural Critique, 48, 65-97. http://dx.doi.org/10.1353/ cul.2001.0033.

${ }^{*}$ Freitag, K., Nilsson, J., Segelström, F., Stoltz, J., Wentzel, J., \& Åberg, K. (2004). Inverkan av Intelligent Cruise Control på trafiksäkerheten [Effects of Intelligent Cruise Control on road safety]. Retrieved from https://www.ida.liu.se/ 729G55/projektrapporter/rapporter-04/grupp7.pdf.

Fuller, R. (2005). Towards a general theory of driver behaviour. Accident Analysis E Prevention, 37, 461-472. http://dx.doi.org/10.1016/j.aap.2004.11.003.

*Funke, G., Matthews, G., Warm, J. S., \& Emo, A. K. (2007). Vehicle automation: A remedy for driver stress? Ergonomics, 50, 1302-1323. http://dx.doi.org/ $10.1080 / 00140130701318830$

Gasser, T. M., \& Westhoff, D. (2012). BASt-study: Definitions of automation and legal issues in Germany. Presentation at the Workshop on the Future of Road Vehicle Automation, Irvine, CA. Retrieved from http://onlinepubs.trb.org/onlinepubs/conferences/2012/Automation/presentations/Gasser.pdf.

Geddes, N. B. (1940). Magic motorways. Random House.

Gehanno, J-F., Rolin, L., \& Darmoni, S. (2013). Is the coverage of google scholar enough to be used alone for systematic reviews. BMC Medical Informatics and Decision Making, 13, 7. http://dx.doi.org/10.1186/1472-6947-13-7.

Gempton, N., Skalistis, S., Furness, J., Shaikh, S., \& Petrovic, D. (2013). Autonomous control in military logistics vehicles: Trust and safety analysis. In D. Harris (Ed.), Engineering psychology and cognitive ergonomics. Applications and services (pp. 253-262). Berlin Heidelberg: Springer. http://dx.doi.org/10.1007/ 978-3-642-39354-9 28.

Glancy, D. J. (2012). Privacy in autonomous vehicles. Santa Clara Law Review, 52, 1171-1561.

Godthelp, J. (1984). Studies of human vehicle control (Doctoral dissertation). TNO, Soesterberg, The Netherlands.

Gold, C., Damböck, D., Lorenz, L., \& Bengler, K. (2013). “Take over!" How long does it take to get the driver back into the loop? In Proceedings of the Human Factors and Ergonomics Society 57th Annual Meeting. San Diego, CA (pp. 1938-1942). http://dx.doi.org/10.1177/1541931213571433.

Gold, C., Lorenz, L., \& Bengler, K. (2014). Influence of automated brake application on take-over situations in highly automated driving scenarios. Maastricht, The Netherlands: FISITA 2014 World Automotive Congress.

Goodall, N. J. (2014a). Ethical decision making during automated vehicle crashes. Retrieved from http://people.virginia.edu/ njg2q/ethics.pdf.

Goodall, N. J. (2014b). Vehicle automation and the duty to act. In 21st World Congress on Intelligent Transport Systems. Detroit, MI. 
Gouy, M., Diels, C., Reed, N., Stevens, A., \& Burnett, G. (2013). Do drivers reduce their headway to a lead vehicle because of the presence of platoons in traffic? A conformity study conducted within a simulator. IET Intelligent Transport Systems, 7, 230-235. http://dx.doi.org/10.1049/iet-its.2012.0156.

Gouy, M., Wiedemann, K., Stevens, A., Brunett, G., \& Reed, N. (2014). Driving next to automated vehicle platoons: How do short time headways influence non-platoon drivers' longitudinal control? Transportation Research Part F: Traffic Psychology and Behaviour, 27, 264-273. http://dx.doi.org/10.1016/j. trf.2014.03.003.

Green, P. (1999). Estimating compliance with the 15-second rule for driver-interface usability and safety. In Proceedings of the Human Factors and Ergonomics Society Annual Meeting, Vol. 43 (pp. 987-991). http://dx.doi.org/10.1177/154193129904301809.

Gugerty, L. (2011). Situation awareness in driving. In J. Lee, M. Rizzo, D. Fischer, \& J. Caird (Eds.), Handbook for driving simulation in engineering, medicine and psychology (pp. 19-265-19-272). Boca Roca, FL: CRC Press. http://dx.doi.org/10.1201/b10836-20.

Hancock, P. A., \& Parasuraman, R. (1992). Human factors and safety in the design of intelligent vehicle-highway systems (IVHS). Journal of Safety Research, 23, 181-198. http://dx.doi.org/10.1016/0022-4375(92)90001-p.

Hand, D. J. (1996). Statistics and the theory of measurement. Journal of the Royal Statistical Society. Series A (Statistics in Society), 159, 445-492. http://dx.doi. org/10.2307/2983326.

Hart, S. G., \& Staveland, L. E. (1988). Development of NASA-TLX (Task Load Index): Results of empirical and theoretical research. In P. A. Hancock \& N. Meshkati (Eds.), Human mental workload (pp. 139-183). Amsterdam, The Netherlands: North Holland Press. Retrieved from http://humanfactors.arc. nasa.gov/groups/TLX/downloads/NASA-TLXChapter.pdf.

Harzing, A. W. (2011). The publish or perish book: A guide to the software. Melbourne: Tarma Software Research.

Hedges, L. V., \& Vevea, J. L. (1998). Fixed-and random-effects models in meta-analysis. Psychological Methods, 3, 486-504. http://dx.doi.org/10.1037//1082989x.3.4.486.

${ }^{*}$ Hoedemaeker, D. M. (1999). Driving with intelligent vehicles - Driving behaviour with Adaptive Cruise Control and the acceptance by individual drivers (Doctoral dissertation, TRAIL thesis series nr 99/6, Delft University Press, Delft). Retrieved from http://repository.tudelft.nl/view/ir/uuid:1fb5010f-7f4f-43ada06f-fb97c5cb6d63/.

${ }^{*}$ Hoedemaeker, D. M., \& Kopf, M. (2001). Visual sampling behaviour when driving with adaptive cruise control. In Proceedings of the 9th International Conference on Vision in Vehicles. Brisbane, Australia (pp. 19-22).

Howard, D., \& Dai, D. (2014). Public perceptions of self-driving cars: The case of Berkeley, California. Transportation Research Board 93rd Annual Meeting (No. 14-4502). Retrieved from http://www.danielledai.com/academic/howard-dai-selfdrivingcars.pdf.

Jacoby, C. C., \& Schuster, S. K. (1997). Issues of automated vehicles operating in mixed traffic. IEEE Conference on Intelligent Transportation System 1997. Boston, MA (pp. 607-612). http://dx.doi.org/10.1109/itsc.1997.660543.

Jamson, A. H., Merat, N., Carsten, O. M., \& Lai, F. C. (2013). Behavioural changes in drivers experiencing highly-automated vehicle control in varying traffic conditions. Transportation Research Part C: Emerging Technologies, 30, 116-125. http://dx.doi.org/10.1016/j.trc.2013.02.008.

Inagaki, T., \& Sheridan, T. B. (2012). Authority and responsibility in human-machine systems: Probability theoretic validation of machine-initiated trading of authority. Cognition, Technology E Work, 14, 29-37. http://dx.doi.org/10.1007/s10111-011-0193-4.

Kassner, A., Muhrer, E., Baumann, M., Vollrath, M., Minin, L., Megard, C., Heers, R. (2011). Integrated human modelling and simulation to support human error risk analysis of partially autonomous driver assistance systems. Knowledge-base of driving without and with PADAS (Attachment to Deliverable D1.3). Retrieved from http://www.transport-research.info/Upload/Documents/201301/20130111_120721_21035_ISI-PADAS-D1.3=KnowledgeBase_Contents.pdf.

Kircher, K., Larsson, A., \& Hultgren, J. A. (2014). Tactical driving behavior with different levels of automation. IEEE Transactions on Intelligent Transportation Systems, 15, 158-167. http://dx.doi.org/10.1109/tits.2013.2277725.

Kondo, S., Asanuma, N., Ishida, S., Ikegaya, M., \& Tanaka, J. (1999). Evaluation of driver assistance system. In Proceedings of the 6th World Congress on Intelligent Transport Systems. Toronto, Canada.

Krause, M., Yilmaz, L., \& Bengler, K. (2014). Comparison of real and simulated driving for a static driving simulator. In T. Ahram, W. Karwowski, \& T. Marek (Eds.), Proceedings of the 5th International Conference on Applied Human Factors and Ergonomics AHFE 2014. Kraków, Poland (pp. 2868-2879).

Kuo, Y. L. (2006). 適應性巡航控制系統對於駕駛績效影響之研究. (MSc thesis). Retrieved from: http://thesis.lib.ncu.edu.tw/ETD-db/ETD-search-c/view_etd? URN=93323112.

Lank, C., Haberstroh, M., \& Wille, M. (2011). Interaction of human, machine, and environment in automated driving systems. Transportation Research Record: Journal of the Transportation Research Board, 2243, 138-145. http://dx.doi.org/10.3141/2243-16.

Larburu, M., Sanchez, J., \& Rodriguez, D. J. (2010). Safe road trains for environment: Human factors' aspects in dual mode transport systems. In Proceedings of the 17th World Congress on Intelligent Transport Systems. Busan, Korea.

Larsson, A. F. (2012). Driver usage and understanding of adaptive cruise control. Applied Ergonomics, 43, 501-506. http://dx.doi.org/10.1016/j. apergo.2011.08.005.

Larsson, A. F., Kircher, K., \& Hultgren, J. A. (2014). Learning from experience: Familiarity with ACC and responding to a cut-in situation in automated driving. Transportation Research Part F: Traffic Psychology and Behaviour, 27, 229-237. http://dx.doi.org/10.1016/j.trf.2014.05.008.

Lee, J. D., McGehee, D. V., Brown, T. L., \& Marshall, D. (2006). Effects of adaptive cruise control and alert modality on driver performance. Transportation Research Record: Journal of the Transportation Research Board, 1980, 49-56. http://dx.doi.org/10.3141/1980-09.

Lee, W. S., Sung, D. H., Lee, J. Y., Kim. Y. S., \& Cho, J. H. (2007). Driving simulation for evaluation of driver assistance systems and driving management systems. In Driving Simulation Conference. North America. Iowa City, IA: University of Iowa.

Levitan, L., \& Bloomfield, J. (1996). Drivers' activities and information needs in an automated highway system (Report No. FHWA-RD-96-066). Washington, DC: US. Government Printing Office.

Levitan, L., Golembiewski, G., \& Bloomfield, J. R. (1998). Human factors issues for automated highway systems. Journal of Intelligent Transportation System, 4, 21-47. http://dx.doi.org/10.1080/10248079808903735.

Lewis-Evans, B., De Waard, D., \& Brookhuis, K. A. (2010). That's close enough-A threshold effect of time headway on the experience of risk, task difficulty, effort, and comfort. Accident Analysis E Prevention, 42, 1926-1933. http://dx.doi.org/10.1016/j.aap.2010.05.014.

Lin, T. W., Hwang, S. L., Su, J. M., \& Chen, W. H. (2008). The effects of in-vehicle tasks and time-gap selection while reclaiming control from adaptive cruise control (ACC) with bus simulator. Accident Analysis E Prevention, 40, 1164-1170. http://dx.doi.org/10.1016/j.aap.2007.12.009.

Lin, T. W., Hwang, S. L., \& Green, P. A. (2009). Effects of time-gap settings of adaptive cruise control (ACC) on driving performance and subjective acceptance in a bus driving simulator. Safety Science, 47, 620-625. http://dx.doi.org/10.1016/j.ssci.2008.08.004.

Lincoln (2014). Lincoln MKS technology features. Retrieved from: http://www.lincoln.com/cars/mks/features/FeatureCategory4.

Llaneras, R. E., Salinger, J., \& Green, C. A. (2013). Human factors issues associated with limited ability autonomous driving systems: Drivers' allocation of visual attention to the forward roadway. In Proceedings of the 7th International Driving Symposium on Human Factors in Driver Assessment, Training, and Vehicle Design. Bolton Landing, NY (pp. 92-98).

Ma, R., \& Kaber, D. B. (2005). Situation awareness and workload in driving while using adaptive cruise control and a cell phone. International Journal of Industrial Ergonomics, 35, 939-953. http://dx.doi.org/10.1016/j.ergon.2005.04.002.

${ }^{*}$ Ma, R. (2006). The effects of in-vehicle automation and reliability on driver situation awareness and trust (Doctoral dissertation). North Carolina State University, Raleigh, NC. Retrieved from http://repository.lib.ncsu.edu/ir/bitstream/1840.16/4155/1/etd.pdf.

Malta, L., Aust, M. L., Faber, F., Metz, B., Saint Pierre, G., Benmimoun, M., \& Schäfer, R. (2012). European large-scale field operational tests on in-vehicle systems. Final results: Impacts on traffic safety (EUROFOT Deliverable D6.4). Aachen, Germany: Ford Forschungszentrum Aachen GmbH. Retrieved from http:// www.eurofot-ip.eu/download/library/deliverables/eurofotsp620121121v11dld64_final_results_impacts_on_traffic_safety.pdf.

Marcus, G. (2012). (November 27). Moral machines. The New Yorker.

*Martens, M. H., Wilschut, E. S., \& Pauwelussen, J. (2008). Semi-autonomous driving: Do drivers still respond to unexpected events? In Proceedings of the 15th World Congress on Intelligent Transport Systems and ITS America's 2008 Annual Meeting. Washington, DC. 
Mayser, C., Piechulla, W., Weiss, K. E., \& König, W. (2003). Driver workload monitoring. In Proceedings of the Internationale Ergonomie-Konferenz der GfA, ISOES und FEES. München, Germany (pp. 7-9).

McCauley, M. E., \& Miller, J. C. (1997). Issues pertaining to the driver's role in automated highway systems (AHS): vigilance, supervisory control, and workload transition (Final Report under contract DTFH-94-C-00067). Washington, DC: Federal Highway Administration.

*McDowell, K., Nunez, P., Hutchins, S., \& Metcalfe, J. S. (2008). Secure mobility and the autonomous driver. IEEE Transactions on Robotics, 24, 688-697. http:// dx.doi.org/10.1109/tro.2008.924261.

Merat, N., \& Jamson, A. H. (2009). How do drivers behave in a highly automated car. In Proceedings of the 5th International Driving Symposium on Human Factors in Driver Assessment, Training and Vehicle Design. Big Sky, MT (pp. 514-521)

Merat, N., Jamson, H., Lai, F., \& Carsten, O. (2010). Automated driving, secondary task performance and situation awareness. In D. de Waard, A. Axelsson, M. Berglund, B. Peters, \& C. Weikert (Eds.), Human Factors: A system view of human, technology, and organisation (pp. 41-53). Maastricht, The Netherlands: Shaker Publishing.

Merat, N., Jamson, A. H., Lai, F. C., \& Carsten, O. (2012). Highly automated driving, secondary task performance, and driver state. Human Factors: The Journal of the Human Factors and Ergonomics Society, 54, 762-771. http://dx.doi.org/10.1177/0018720812442087.

Merat, N., \& Lee, J. D. (2012). Preface to the special section on human factors and automation in vehicles designing highly automated vehicles with the driver in mind. Human Factors: The Journal of the Human Factors and Ergonomics Society, 54, 681-686. http://dx.doi.org/10.1177/0018720812461374.

Merat, N., Jamson, A. H., Lai, F., Daly, M., \& Carsten, O. M. (2014). Transition to manual: Driver behaviour when resuming control from a highly automated vehicle. Transportation Research Part F: Traffic Psychology and Behaviour, 26, 1-9. http://dx.doi.org/10.1016/j.trf.2014.05.006.

Michon, J. A. (Ed.). (1993). Generic intelligent driver support. A comprehensive report on GIDS. London: Taylor \& Francis.

National Automated Highway System Consortium (NAHSC), (1998). C3 Interim Report: Phase 1 October 1996 to March 1998. Troy, MI, USA: National Automated Highway System Consortium.

National Highway Traffic Safety Administration (NHTSA), (2012). Visual-manual NHTSA driver distraction guidelines for in-vehicle electronic devices. Washington, DC: National Highway Traffic Safety Administration (NHTSA), Department of Transportation (DOT). Retrieved from http://www.nhtsa.gov/ staticfiles/rulemaking/pdf/Distraction_NPFG-02162012.pdf.

Neale, V. L., \& Dingus, T. A. (1998). Commentaries in: Human Factors issues for automated highway systems (AHS). Intelligent Transportation Systems Journal: Technology, Planning, and Operations, 4, 111-119. http://dx.doi.org/10.1080/10248079808903740.

Neubauer, C., Matthews, G., Saxby, D., \& Langheim, L. (2010). Simulator methodologies for investigating fatigue and stress in the automated vehicle. Advances in Transportation Studies, 2010 Special Issue.

Neubauer, C., Matthews, G., Saxby, D., \& Langheim, L. (2011). Individual differences and automation choice in simulated driving. In Proceedings of the Human Factors and Ergonomics Society Annual Meeting, Vol. 55 (pp. 1563-1567). http://dx.doi.org/10.1177/1071181311551326.

Neubauer, C., Matthews, G., Langheim, L., \& Saxby, D. (2012). Fatigue and voluntary utilization of automation in simulated driving. Human Factors: The Journal of the Human Factors and Ergonomics Society, 54, 734-746. http://dx.doi.org/10.1177/0018720811423261.

*Nilsson, L. (1995). Safety effects of adaptive cruise controls in critical traffic situations. In Proceedings of Steps Forward. Intelligent Transport Systems World Congress. Yokohama, Japan (pp. 1254-1259).

*Nilsson, L., \& Nåbo, A. (1996). Evaluation of application 3: Intelligent cruise control simulator experiment. (Report No. 266). Linköping, Sweden: VTI Särtryck.

Nilsson, L. (2005). Automated driving does not work without the involvement of the driver. In G. Underwood (Ed.), Traffic and transport psychology: Theory and application (pp. 293-301). Amsterdam, The Netherlands: Elsevier Ltd.

Nilsson, J., Strand, N., Falcone, P., \& Vinter, J. (2013). Driver performance in the presence of adaptive cruise control related failures: Implications for safety analysis and fault tolerance. In Proceedings of the 43rd Annual IEEE/IFIP Conference on Dependable Systems and Networks Workshop. Budapest, Hungary (pp. 1-10). http://dx.doi.org/10.1109/dsnw.2013.6615531.

Nirschl, G., \& Kopf, M. (1997). Untersuchung des Zusammenwirkens zwischen dem Fahrer und einem ACC-System in Grenzsituationen. VDI Berichte, 1317, $119-148$.

Norman, D. A. (1990). The 'problem' with automation: Inappropriate feedback and interaction, not 'over-automation'. Philosophical Transactions of the Royal Society of London. B, Biological Sciences, 327, 585-593. http://dx.doi.org/10.1098/rstb.1990.0101.

Nowakowski, C., O'Connell, J., Shladover, S. E., \& Cody, D. (2010). Cooperative adaptive cruise control: Driver acceptance of following gap settings less than one second. In Proceedings of the Human Factors and Ergonomics Society Annual Meeting, Vol. 54 (pp. 2033-2037). http://dx.doi.org/10.1037/e578852012-003.

Noy, Y. I., Vredenburgh, A., Hornick, R., Savaglio, B., Mortimer, R. G., Olsen, R., Spangler, J. R. (2000). Mock trial: Human Factors contributions to litigation involving adaptive cruise control. In Proceedings of the Human Factors and Ergonomics Society Annual Meeting, Vol. 44 (pp. 398-398). http://dx.doi.org/ $10.1177 / 154193120004403408$.

Oberholtzer, J., Yee, S., Green, P. A., Eoh, H., Nguyen, L., \& Schweitzer, J. (2007). Frequency of distracting tasks people do while driving: An analysis of the ACAS FOT data (Technical Report No. UMTRI-2006-17). Ann Arbor, MI: Transportation Research Institute (UMTRI)

Omae, M., Hashimoto, N., Sugamoto, T., \& Shimizu, H. (2005). Measurement of driver's reaction time to failure of steering controller during automatic driving. Review of Automotive Engineering, 26, 213-215.

Parasuraman, R., \& Riley, V. (1997). Humans and automation: Use, misuse, disuse, abuse. Human Factors: The Journal of the Human Factors and Ergonomics Society, 39, 230-253. http://dx.doi.org/10.1518/001872097778543886.

Parasuraman, R., Sheridan, T. B., \& Wickens, C. D. (2008). Situation awareness, mental workload, and trust in automation: Viable, empirically supported cognitive engineering constructs. Journal of Cognitive Engineering and Decision Making, 2, 140-160. http://dx.doi.org/10.1518/155534308x284417.

Park, J., Sung, D., \& Lee, W. S. (2006). A driving simulator study on adaptive cruise control failure. In Proceedings of the International Joint Conference SICEICASE. Busan, South Korea (pp. 2138-2141). http://dx.doi.org/10.1109/sice.2006.315566.

Petermann-Stock, I., Hackenberg, L., Muhr, T., \& Mergl, Ch. (2013). Wie lange braucht der Fahrer? Eine Analyse zu Übernahmezeiten aus verschiedenen Nebentätigkeiten während einer hochautomatisierten Staufahrt. Tagung Fahrerassistenz: Der Weg zum automatischen Fahren, November 2013, München.

*Peters, B. (2001). Adaptation evaluation: An adaptive cruise control system used by drivers with lower limb disabilities. IATSS Research, 25, 51-60.

Piccinini, G. B., Prati, G., Pietrantoni, L., Manzini, C., Rodrigues, C. M., \& Leitão, M. (2013). Drivers' hand positions on the steering wheel while using Adaptive Cruise Control (ACC) and driving without the system. In D. de Waard, K. Brookhuis, R. Wiczorek, F. di Nocera, R. Brouwer, P. Barham, C. Weikert, A. Kluge, W. Gerbino, \& A. Toffetti (Eds.), Proceedings of the Human Factors and Ergonomics Society Europe Chapter 2013 Annual Conference. Torino, Italy (pp. 207-216). Retrieved from http://www.hfes-europe.org/books/proceedings2013/Piccinini.pdf.

Pohl, J., \& Ekmark, J. (2003). A lane keeping assist system for passenger cars-design aspects of the user interface. In Proceedings of the 18th International Technical Conference on the Enhanced Safety of Vehicles. Nagoya, Japan.

Quintana, E. (2008). The ethics and legal implications of military unmanned vehicles (Occasional paper). London, UK: Royal United Services Institute for Defence and Security Studies.

Radlmayr, J., Gold, C., \& Bengler, K. (in press). How traffic situations and non-driving related tasks affect the take-over quality in highly automated driving. In Proceedings of the Human Factors and Ergonomics Society 58th Annual Meeting. Chicago, Illinois.

Rajaonah, B., Tricot, N., Anceaux, F., \& Millot, P. (2008). The role of intervening variables in driver-ACC cooperation. International Journal of Human-Computer Studies, 66, 185-197. http://dx.doi.org/10.1016/j.ijhcs.2007.09.002.

Rogers, M., Zhang, Y., Kaber, D., Liang, Y., \& Gangakhedkar, S. (2011). The effects of visual and cognitive distraction on driver situation awareness. In D. Harris (Ed.), Engineering psychology and cognitive ergonomics (pp. 186-195). Berlin Heidelberg: Springer. http://dx.doi.org/10.1007/978-3-642-21741-8 21.

*Rudin-Brown, C. M., \& Parker, H. A. (2004). Behavioural adaptation to adaptive cruise control (ACC): Implications for preventive strategies. Transportation Research Part F: Traffic Psychology and Behaviour, 7, 59-76. http://dx.doi.org/10.1016/j.trf.2004.02.001.

Saffarian, M., De Winter, J. C. F., \& Happee, R. (2012). Automated driving: Human-factors issues and design solutions. In Proceedings of the Human Factors and Ergonomics Society Annual Meeting, Vol. 56 (pp. 2296-2300). http://dx.doi.org/10.1177/1071181312561483. 
*Saffarian, M., Happee, R., \& De Winter, J. C. F. (2012). Why do drivers maintain short headways in fog? A driving-simulator study evaluating feeling of risk and lateral control during automated and manual car following. Ergonomics, 55, 971-985. http://dx.doi.org/10.1080/00140139.2012.691993.

Salinger, J. (2012). Human factors for limited-ability autonomous driving systems. Presented at the Transportation Research Board Road Vehicle Automation Workshop, Irvine, CA. Retrieved from http://onlinepubs.trb.org/onlinepubs/conferences/2012/Automation/presentations/Salinger.pdf.

Sarter, N. B., \& Woods, D. D. (1991). Situation awareness: A critical but ill-defined phenomenon. The International Journal of Aviation Psychology, 1, 45-57. http://dx.doi.org/10.1207/s15327108ijap0101_4.

*Saxby, D. J., Matthews, G., Warm, J. S., Hitchcock, E. M., \& Neubauer, C. (2013). Active and passive fatigue in simulated driving: Discriminating styles of workload regulation and their safety impacts. Journal of Experimental Psychology: Applied, 19, 287-300. http://dx.doi.org/10.1037/a0034386.

Sayer, J. R., Mefford, M. L., Shirkey, K., \& Lantz, J. (2005). Driver distraction: A naturalistic observation of secondary behaviors with the use of driver assistance systems. In Proceedings of the Third International Driving Symposium on Human Factors in Driver Assessment, Training and Vehicle Design. Rockport, Maine (pp. 262-268).

*Schermers, G., Malone, K. M., \& Van Arem, B. (2004). Dutch Evaluation of Chauffeur Assistant (DECA): Traffic flow effects of implementation in the heavy goods vehicles sector. ITS World Congress, Nagoya, Aichi.

Schieben, A., Flemish, F., Martens, M., Wilschut, E., Rambaldini, A., Tofetti, A., Turi, G., Arduino, C., Merat, N., \& Jamson, H. (2008). Test results of HMI in use on cars and with simulators (CityMobil Deliverable 3.2.2), EU DG Research.

Schieben, A., Temme, G., Köster, F., \& Flemisch, F. (2011). How to interact with a highly automated vehicle-generic interaction design schemes and test results of a usability assessment. In D. de Waard, N. Gérard, L. Onnasch, R. Wiczorek, \& D. Manzey (Eds.), Human Centred Automation (pp. 251-266). Maastricht, The Netherlands: Shaker Publishing.

Sears, D. O. (1986). College sophomores in the laboratory: Influences of a narrow data base on social psychology's view of human nature. Journal of Personality and Social Psychology, 51, 515-530. http://dx.doi.org/10.1037//0022-3514.51.3.515.

Seiniger, P., Westhoff, D., Fahrenkrog, F., \& Zlocki, A. (2011). Interactive. Accident avoidance by active intervention for intelligent vehciles. Legal aspects (Deliverable D7.3). Aachen, Germany: Ford Research \& Advanced Engineering. Retrieved from http://www.transport-research.info/Upload/Documents/ 201210/20121024_135222_97170_interactIVe-SP7-20110802v12-DL-D7.3-Legal_Aspects.pdf.

Seppelt, B. D., \& Lee, J. D. (2007). Making adaptive cruise control (ACC) limits visible. International Journal of Human-Computer Studies, 65, 192-205. http://dx. doi.org/10.1016/j.ijhcs.2006.10.001.

Shariff, S. Z., Bejaimal, S. A., Sontrop, J. M., Iansavichus, A. V., Haynes, R. B., Weir, M. A., et al. (2013). Retrieving clinical evidence: A comparison of PubMed and Google Scholar for quick clinical searches. Journal of Medical Internet Research, 15. http://dx.doi.org/10.2196/jmir.2624.

Sheridan, T. B. (1970). Big brother as driver: New demands and problems for the man at the wheel. Human Factors: The Journal of the Human Factors and Ergonomics Society, 12, 95-101.

Sheridan, T. B. (2004). Humans and automation: System design and research issues. Santa Monica: Wiley.

Shladover, S. E. (1995). Review of the state of development of advanced vehicle control systems (AVCS). Vehicle System Dynamics, 24, 551-595. http://dx.doi. org/10.1080/00423119508969108.

Shladover, S. E. (1998). Why we should develop a truly automated highway system. Transportation Research Record: Journal of the Transportation Research Board, 1651, 66-73. http://dx.doi.org/10.3141/1651-10.

Siebert, F. W., Oehl, M., \& Pfister, H. R. (2014). The influence of time headway on subjective driver states in adaptive cruise control. Transportation Research Part F: Traffic Psychology and Behaviour, 25, 65-73. http://dx.doi.org/10.1016/j.trf.2014.05.005.

Skottke, E. M., Debus, G., Wang, L., \& Huestegge, L. (in press). Carryover effects of highly automated convoy driving on subsequent manual driving performance. Human Factors: The Journal of the Human Factors and Ergonomics Society. http://dx.doi.org/10.1177/0018720814524594.

Smith, B. W. (2013). SAE levels of driving automation. Retrieved from http://cyberlaw.stanford.edu/loda.

Spiessl, W., \& Mangold, M. (2010). ALCT-a methodical approach toward evaluating the influence of secondary tasks during automated driving. In Proceedings of the European Conference. Human Centred Design for Intelligent Transport Systems. Berlin, Germany (pp. 379-388).

*Stanton, N. A., Young, M., \& McCaulder, B. (1997). Drive-by-wire: The case of driver workload and reclaiming control with adaptive cruise control. Safety Science, 27, 149-159. http://dx.doi.org/10.1016/s0925-7535(97)00054-4.

Stanton, N. A., \& Young, M. S. (2000). A proposed psychological model of driving automation. Theoretical Issues in Ergonomics Science, 1, 315-331. http://dx. doi.org/10.1080/14639220052399131.

*Stanton, N. A., Young, M. S., Walker, G. H., Turner, H., \& Randle, S. (2001). Automating the driver's control tasks. International Journal of Cognitive Ergonomics, 5, 221-236. http://dx.doi.org/10.1207/s15327566ijce0503_5.

Stanton, N. A., \& Young, M. S. (2005). Driver behaviour with adaptive cruise control. Ergonomics, 48, 1294-1313. http://dx.doi.org/10.1080/ 00140130500252990.

Stanton, N. A., Dunoyer, A., \& Leatherland, A. (2011). Detection of new in-path targets by drivers using Stop \& Go Adaptive Cruise Control. Applied Ergonomics, 42, 592-601. http://dx.doi.org/10.1016/j.apergo.2010.08.016.

Sterling, B. S., Perala, C. H., \& Blaske, S. F. (2007). Workload and stress of crews operating future manned vehicles (No. ARL-TR-4023). Aberdeen Proving Ground, MD: U.S. Army Research Laboratory, Human Research \& Engineering Directorate.

Strand, N., Nilsson, J., Karlsson, I. C., \& Nilsson, L. (2014). Semi-automated versus highly automated driving in critical situations caused by automation failures. Transportation Research Part F: Traffic Psychology and Behaviour, 27, 218-228. http://dx.doi.org/10.1016/j.trf.2014.04.005.

Szalma, J. L., Warm, J. S., Matthews, G., Dember, W. N., Weiler, E. M., Meier, A., et al. (2004). Effects of sensory modality and task duration on performance, workload, and stress in sustained attention. Human Factors: The Journal of the Human Factors and Ergonomics Society, 46, 219-233. http://dx.doi.org/ 10.1518/hfes.46.2.219.37334.

Takada, Y., \& Shimoyama, O. (2001). Evaluation of driving-assistance systems based on drivers' workload. In: McGehee, D.V., Lee, J.D., Rizzo, M., Holeton, K. \& Lopes, T. (Eds.), Proceedings of the International Driving Symposium on Human Factors in Driver Assessment Training and Vehicle Design. Aspen, CO (pp. 208-213). University of Iowa, Iowa City.

Takano, W., \& Kobayashi, T. (2004). A study of evaluation for driver's mental workload while driving heavy duty vehicle with ACC including EBS brake control. In Proceedings of the JSAE Annual Congress (No. 5-04).

*Tango, F., Minin, L., Aras, R., \& Pietquin, O. (2011). Automation effects on driver's behaviour when integrating a PADAS and a distraction classifier. In V. G. Duffy (Ed.), Digital human modeling (pp. 503-512). Berlin Heidelberg: Springer. http://dx.doi.org/10.1007/978-3-642-21799-9_56.

Thompson, L. K., \& Tönnis, M. (2007). Facing diversity when designing and evaluating driver support systems. In R. N. Pikaar, E. A. P. Koningsveld, \& P. J. M. Settels (Eds.), Meeting diversity in ergonomics (pp. 289-308). Elsevier Ltd. http://dx.doi.org/10.1016/b978-008045373-6/50018-0.

Thorpe, C., Jochem, T., \& Pomerleau, D. (1997). The 1997 automated highway free agent demonstration. In Proceedings of the IEEE Conference on Intelligent Transportation System. Boston, MA (pp. 496-501). http://dx.doi.org/10.1109/itsc.1997.660524.

*Törnros, J., Nilsson, L., Ostlund, J., \& Kircher, A. (2002). Effects of ACC on driver behaviour, workload and acceptance in relation to minimum time headway. In Proceedings of the 9th World Congress on Intelligent Transport Systems. Washington, DC.

Toyota (2013). 2013 Lexus LS Advanced Active Safety Features/2013 Consumer Electronics Show. Retrieved from http://www.toyota.com/esq/pdf/The\% 202013\%20LS\%20Advanced\%20Active\%20Safety\%20(2).pdf.

Underwood, S. E. (1992). Delphi forecast and analysis of intelligent vehicle-highway systems through 1991: Delphi II (IVHS Technical Report 92-17). Ann Arbor, MI: University of Michigan Transportation Research Institute.

United Nations (1968). Convention on road traffic. Done at Vienna on 8 November 1968. Amendment 1. Retrieved from http://www.unece.org/fileadmin/ DAM/trans/conventn/crt1968e.pdf.

*Uyttendaele, A. J., \& Terken, J. M. B. (2014). Mental workload of ITS systems for car following on driver mental workload. Unpublished manuscript. 
Van den Beukel, A. P., \& Van der Voort, M. C. (2013). The influence of time-criticality on situation awareness when retrieving human control after automated driving. In 16th International IEEE Annual Conference on Intelligent Transportation System, 2013. The Hague, The Netherlands (pp. 2000-2005). http://dx.doi. org/10.1109/itsc.2013.6728523.

*Van der Hulst, M., Rothengatter, J. A., \& Heino, A. (1996). Effectiveness of distance-keeping support systems. In Handbook International Conference on Traffic and Transport Psychology (pp. 179-184). Valencia: INTRAS.

Van Driel, C. J. G., \& Van Arem, B. (2006). Impacts of a congestion assistant on driving behaviour, workload and acceptance: Results from a driving simulator study. Enschede, The Netherlands: University of Twente, Centre for Transport Studies.

Verne, J. (1996). Paris in the twentieth century. Del Rey/Ballantine Books.

Verplank, W. L. (1977). Is there an optimal work-load in manual control? (Doctoral dissertation). MIT.

Victor, T. W., Harbluk, J. L., \& Engström, J. A. (2005). Sensitivity of eye-movement measures to in-vehicle task difficulty. Transportation Research Part F: Traffic Psychology and Behaviour, 8, 167-190. http://dx.doi.org/10.1016/j.trf.2005.04.014.

*Vollrath, M., Briest, S., \& Oeltze, K. (2010). Auswirkungen des Fahrens mit Tempomat und ACC auf das Fahrerverhalten (Fahrzeugtechnik Heft F 74). Braunschweig: Deutsches Zentrum für Luft- und Raumfahrt e.V. (DLR).

Vollrath, M., Schleicher, S., \& Gelau, C. (2011). The influence of Cruise Control and Adaptive Cruise Control on driving behaviour - A driving simulator study. Accident Analysis E' Prevention, 43, 1134-1139. http://dx.doi.org/10.1016/j.aap.2010.12.023.

Volvo (2004). Final report: Phase II driver survey report: Volvo intelligent vehicle initiative field operational test. U.S. Department of Transportation Washington DC. Retrieved from http://ntl.bts.gov/lib/jpodocs/repts_te/14122_files/14122.pdf.

Volvo (2013) (July 5). Volvo Car Group reveals world-class safety and support features that will be introduced in the all-new XC90 in 2014 [Press release]. Retrieved from https://www.media.volvocars.com/global/en-gb/media/pressreleases/49875/volvo-cars-reveals-world-class-safety-and-supportfeatures-to-be-introduced-in-the-all-new-xc90-in-2.

Ward, N. J., Fairclough, S., \& Humphreys, M. (1995). The effect of task automatisation in the automotive context: A field study of an Autonomous Intelligent Cruise Control system. In Proceedings of the International Conference on Experimental analysis and Measurement of Situation Awareness. Daytona Beach, FL.

Warm, J. S., Parasuraman, R., \& Matthews, G. (2008). Vigilance requires hard mental work and is stressful. Human Factors: The Journal of the Human Factors and Ergonomics Society, 50, 433-441. http://dx.doi.org/10.1518/001872008x312152.

Watanabe, T., Kishimoto, N., Hayafune, K., Yamada, K., \& Maede, N. (1995). Development of an intelligent cruise control system. Presented at Steps Forward. Intelligent Transport Systems World Congress. Yokohama, Japan (pp. 1229-1235).

Wille, M., Röwenstrunk, M., \& Debus, G. (2007). Konvoi: Electronically coupled truck-convoy. In D. de Waard, F. O. Flemisch, B. Lorenz, H. Oberheid, \& K. A. Brookhuis (Eds.), Human Factors for assistance and automation (pp. 243). Maastricht, The Netherlands: Shaker Publishing.

Young, K. L., Salmon, P. M., \& Cornelissen, M. (2012). Missing links? The effects of distraction on driver situation awareness. Safety Science, 56, 36-43. http:// dx.doi.org/10.1016/j.ssci.2012.11.004.

*Young, M. S. (2000). Attention, automaticity, and automation: New perspectives on mental underload and performance (Doctoral dissertation). University of Southampton, UK.

Young, M. S., \& Stanton, N. A. (2002). Malleable attentional resources theory: A new explanation for the effects of mental underload on performance. Human Factors: The Journal of the Human Factors and Ergonomics Society, 44, 365-375. http://dx.doi.org/10.1518/0018720024497709.

*Young, M. S., \& Stanton, N. A. (2004). Taking the load off: Investigations of how adaptive cruise control affects mental workload. Ergonomics, 47, $1014-1035$. http://dx.doi.org/10.1080/00140130410001686348.

*Young, M. S., \& Stanton, N. A. (2007). What's skill got to do with it? Vehicle automation and driver mental workload. Ergonomics, 50, 1324-1339. http://dx. doi.org/10.1080/00140130701318855. 